Article

\title{
Investigations into Synoptic Spatiotemporal Characteristics of Coastal Upper Ocean Circulation Using High Frequency Radar Data and Model Output
}

\author{
Lei Ren ${ }^{1,2,3}$, Nanyang Chu ${ }^{4, *}$, Zhan $\mathrm{Hu}^{4}$ and Michael Hartnett ${ }^{5,6}$ \\ 1 School of Marine Engineering and Technology, Sun Yat-sen University, Zhuhai 519082, China; \\ renlei7@mail.sysu.edu.cn \\ 2 Southern Marine Science and Engineering Guangdong Laboratory (Zhuhai), Zhuhai 519082, China \\ 3 Institute of Estuarine and Coastal Research, Sun Yat-sen University, Zhuhai 519082, China \\ 4 School of Marine Science, Sun Yat-sen University, Zhuhai 519082, China; huzh9@mail.sysu.edu.cn \\ 5 School of Engineering and Informatics, National University of Ireland Galway, H91 TH33 Galway, Ireland; \\ michael.hartnett@nuigalway.ie \\ 6 Ryan Institute, National University of Ireland Galway, H91 TH33 Galway, Ireland \\ * Correspondence: chuny@mail2.sysu.edu.cn
}

Received: 20 July 2020; Accepted: 29 August 2020; Published: 1 September 2020

\begin{abstract}
Numerical models and remote sensing observation systems such as radars are useful for providing information on surface flows for coastal areas. Evaluation of their performance and extracting synoptic characteristics are challenging and important tasks. This research aims to investigate synoptic characteristics of surface flow fields through undertaking a detailed analysis of model results and high frequency radar (HFR) data using self-organizing map (SOM) and empirical orthogonal function (EOF) analysis. A dataset of surface flow fields over thirteen days from these two sources was used. A SOM topology map of size $4 \times 3$ was developed to explore spatial patterns of surface flows. Additionally, comparisons of surface flow patterns between SOM and EOF analysis were carried out. Results illustrate that both SOM and EOF analysis methods are valuable tools for extracting characteristic surface current patterns. Comparisons indicated that the SOM technique displays synoptic characteristics of surface flow fields in a more detailed way than EOF analysis. Extracted synoptic surface current patterns are useful in a variety of applications, such as oil spill treatment and search and rescue. This research provides an approach to using powerful tools to diagnose ocean processes from different aspects. Moreover, it is of great significance to assess SOM as a potential forecasting tool for coastal surface currents.
\end{abstract}

Keywords: ocean surface circulation; high frequency radar; self-organizing map; empirical orthogonal function; neural networks; synoptic characteristics

\section{Introduction}

Surface currents primarily driven by winds can flow for thousands of kilometers and can reach depths of hundreds of meters. Their movements carry heat and mass from place-to-place about the Earth system. Understanding of surface current patterns in coastal regions is of great importance for a variety of aspects, such as the development of marine economics and environmental protection [1]. As remote sensing technologies advance, surface currents can be measured not only at a single or few locations by instruments such as an Acoustic Doppler Current Profiler (ADCP), but can be recorded by tools such as radars over large coastal domains with high spatial and temporal resolutions. Understanding, mining, and application of these surface flow field data are a new challenge for researchers [2]. Several researchers have recently undertaken investigations on measured surface flow 
fields. They have used surface radar data to validate model results, to improve modeling performance through data assimilation, to establish statistical forecasting models, and to characterize the physical process of surface water bodies [3-6].

With the increasing availability of surface current data, investigations into patterns of surface currents have been undertaken using various analysis techniques such as empirical orthogonal function (EOF) (or principal component analysis (PCA)), k-means, and self-organizing map (SOM) to extract patterns of variability in meteorological and oceanographic data. In essence, EOF and PCA are the same, but their focus is different. PCA is the eigenvalue and eigenvector obtained from the covariance matrix, and EOF is computed using the cross matrix of anomaly values, so the calculated eigenvectors are the same, while the latter is $\mathrm{n}$ times the former ( $\mathrm{n}$ is the sample size). PCA, multidimensional scaling (MDS), and SOM are representative unsupervised machine learning techniques. The PCA technique summarizes the dispersion of datasets as a data cloud through converting the original dataset into a set of principal components; the MDS technique takes a set of dissimilarities and returns a set of points such that the distances between points are approximately equal to the dissimilarities [7]. The classical MDS technique is the same as the PCA technique if the input dataset distances are Euclidean [8]. Liu, et al. [9] used EOF and SOM to extract synoptic characteristic patterns of ocean currents at the West Florida Shelf area, and found that flow field patterns extracted by SOM are more accurate and intuitive than those obtained from the leading mode patterns with EOF analysis. This is probably because EOF is a linear extraction tool, whereas SOM is a nonlinear extraction tool; properties of nonlinearity extraction in SOM can better describe nonlinear dynamic oceanic processes. Soto-Navarro, et al. [10] applied EOF decomposition to compare the main flow pattern from model and radar, and found that both systems show satisfactory agreement for the first two EOF modes, while the agreement is less for the third EOF mode. Moreover, because wind data collected in a single station close to the coast were used in the model, correlation of the third principal component (PC) between model and radar was very low $(<0.1)$. They demonstrated that results from that principal components are representative of the entire study domain. Reusch, et al. [11] compared the SOM method with the PCA method for extracting patterns of variability for North Atlantic sea level pressure fields and found that SOM was more robust than PCA. In addition, comparisons between the SOM method and the k-means method were performed by Lobo [12], Lin and Chen [13], and Solidoro, et al. [14]. Their results indicated that SOM generates more accurate patterns than k-means, and SOM in general is more flexible than k-means. Moreover, the SOM method has been broadly applied among disparate range of disciplines such as meteorology (sea level pressure, air temperature, humidity, evaporation, precipitation, cloud, and wind data) and oceanography (satellite ocean color and chlorophyll, biological and geochemical data, sea surface temperature (SST), sea surface height (SSH), and ocean currents) as a data mining and visualization method for complex datasets [15-21]. These studies demonstrate that SOM is a robust, efficient, and concise method to project high dimensional data onto a low dimensional (usually two-dimensional) map for characterizing synoptic patterns. Thus, in this research, SOM was applied to extract synoptic characteristic patterns of coastal ocean flow fields based on hourly HFR measurements and model results at a site off the west coast of Ireland.

Several researchers have previously applied SOM techniques to extract characteristic patterns in physical oceanography from in situ observations and model results. Liu and Weisberg [22] examined patterns of ocean current variability using time series of moored ADCP velocity data based on EOF and SOM. Three characteristic spatial patterns were extracted: (i) spatially coherent southeastward, (ii) northwestward flow patterns with strong currents, and (iii) a transition pattern of weak currents. Based on comparisons between results from EOF and SOM, they found that the SOM had advantages over the EOF in both pattern recognition and description. Subsequently, Liu, et al. [23] applied SOM to extract patterns from a linear progressive sine wave signal, and analyzed the effects of the SOM tunable parameters on the extracted patterns. Effects of varying SOM map size, map lattice structure, and neighborhood function were examined as well. Liu, et al. [23] found that (a) a larger SOM map size led to slightly more accurate mapping, (b) a rectangular lattice was preferable for a small-size 
SOM and a hexagonal lattice may be useful for larger map sizes, (c) linear initialization provided better SOM results than random initialization, (d) the "ep" (or Epanechikov, see details in Appendix A) type is the best neighborhood function and gave the best results. Liu, et al. [24] also investigated the spatial structure and temporal evolution of distinct physical processes on the West Florida Shelf (WFS) based on patterns of ocean current variability from a joint HFR and ADCP dataset using SOM. Semidiurnal, diurnal, and subtidal frequency bands were separately examined with SOM analysis. Results indicated that SOM is an effective analysis tool for identifying modulated, heterogeneous, anisotropic, three-dimensional coastal ocean current variations observed by HFR and ADCPs [24].

Mihanović, et al. [25] extracted subtidal frequency patterns from HFR surface flow fields in the northern Adriatic using SOM. Since surface current patterns were strongly influenced by local wind forcing, a joint dataset including contemporaneous surface wind data obtained from the operational hydrostatic mesoscale meteorological model ALADIN/HR was used. Their analysis found that the strongest currents observed during energetic bora episodes were represented by several current patterns and another characteristic wind, the sirocco, which was represented by three SOM current patterns. Mihanović, et al. [25] suggested that SOM was a most valuable tool for extracting characteristic patterns of surface flows and forcing functions. Vilibic, et al. [26] applied the SOM method to predict surface currents based on HFR measurements and numerical weather prediction (NWP) data for the northern Adriatic in comparison with operational ROMS-produced surface currents. They found that the SOM-based forecasting system had a slightly better forecasting skill than the ROMS model, especially during strong wind conditions. Liu, et al. [9] applied the SOM method to extract patterns of the loop current system and to identify altimetry sea surface height variability in the eastern Gulf of Mexico. Jin, et al. [27] studied the variability of current patterns near the Karama Gap using outputs from the ocean general circulation model (OGCM) for the earth simulator on the basis of the SOM. Jin, et al. [27] found that the evolution of the four coherent patterns showed a robust cycle characterized as a counterclockwise trajectory in the SOM space. Tsui and Wu [17] applied SOM to study the Kuroshio intrusion into the South China Sea (SCS) through the Luzon Strait using 18 years of archiving, validation, and interpretation of satellite oceanographic (AVISO) mean geostrophic velocity (GSV) data. Results indicate that the Kuroshio intrusion may occur year-round; intrusion is not a major characteristic in the study area and winter intrusion events are more frequent than summer ones, based on seasonal variability.

The SOM technique is in a sense a combination of both PCA and MDS techniques. SOM is a type of cluster analysis, which organizes a dataset of patterns into clusters based on similarity. Grouping a given dataset of unlabeled patterns into meaningful clusters is the main problem that is solved in SOM. Moreover, SOM was used to develop a drought forecast model through a nonlinear mapping of the input domain onto a two-dimensional grid by Barros and Bowden [28]; results indicated that SOM-based data models can be tools of discovery to identify nonlinear diagnostic and prognostic relationships among datasets. Obach, et al. [29] used radial basis function networks combined with a SOM to predict annual abundance of aquatic insects, and found that it is possible to predict the abundance of aquatic insects based on relevant environmental factors. SOM can be employed not only to reduce the size of the dataset by clustering, but also to construct a nonlinear projection of the dataset onto a low dimensional display that are usually of one or two dimensions [30].

Previous studies indicated that SOM is a useful and effective tool for dealing with large datasets. Since there were few records of surface current measurements, in either space or time, available in the Galway Bay area before the deployment of HFR system, previous studies of the bay generally provide little information on spatial patterns of surface currents [31-33]. Herein, both SOM and EOF techniques were applied to investigate synoptic characteristics of surface currents from both numerical models and a HFR system. Additionally, some previous research considered longer term analysis. During this research, because datasets were incomplete, gap filling was used to develop a "synthetic" dataset. The research presented herein considers a small dataset, one of the reasons for this is so that we use only actual data during the analysis and do not introduce extraneous uncertainties; this type of 
analysis has not previously been carried out. In subsequent research, we will consider longer datasets that have been synthetically enhanced to provide continuous signals and then compare results with those from this current research.

The structure of this paper is as follows. Section 2 presents methodologies, including the research domain, observational data, numerical model, and SOM and EOF methods. Results and discussion are presented in Section 3, followed by research conclusions in Section 4.

\section{Methodologies}

\subsection{Research Domain}

Galway Bay is located on the west coast of Ireland; it is a semiclosed bay, as shown in Figure 1. Its length from west to east is approximately $62 \mathrm{~km}$ and the mouth of the bay from north to south is approximately $33 \mathrm{~km}$. Regional climate in Galway Bay area is mainly affected by the Atlantic Climate and prevailing southwesterly winds. Tides in this area are semidiurnal, ranging from $5 \mathrm{~m}$ during spring tides to $2.5 \mathrm{~m}$ during neap tides [34]. The average water depth is approximately $30 \mathrm{~m}$ for the area covered by the HFR system.
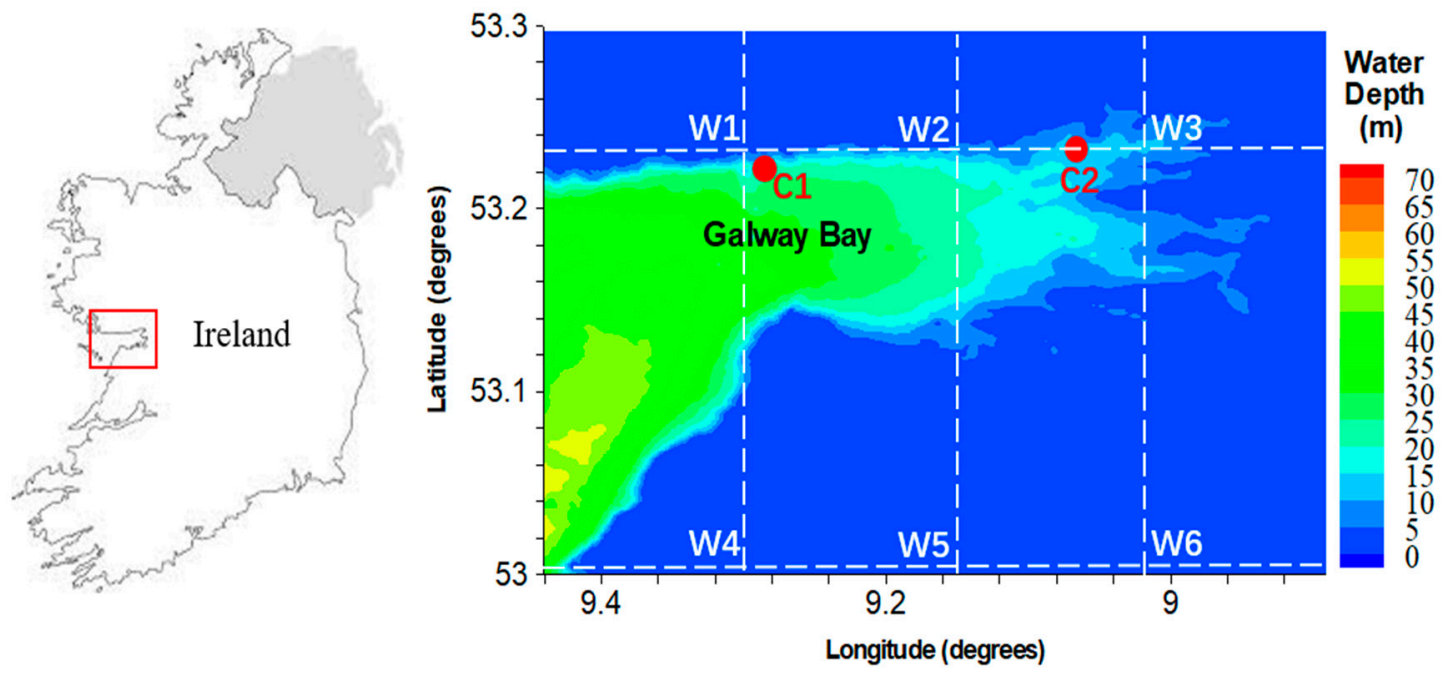

Figure 1. Deployment of the high frequency radar (HFR) system (C1 and C2 indicate deployment location of HFR station).

\subsection{Observational Data}

Land-based coastal radar systems are capable of monitoring information of surface waters based on the application of high frequency radio wave backscatter [35]. Radars operating in the HF band can measure the Doppler shift of radio waves scattered from ocean surface gravity waves [36-39]. A single radar station determines radial components of surface currents relative to that station, providing current magnitudes and directions toward or away from the station. Surface flow fields are determined by synthesizing radial surface velocity components from two or more radars. The extent of alongshore surface current mapping is limited only by the number of radar stations with overlapping coverage [40]. Spatial coverage of surface currents measured by radars can reach approximately $200 \mathrm{~km}$ depending on the radar transmitting frequency. Information obtained from radar has a large number of applications, such as analysis of marine renewable energy resources, oil-spill monitoring [41,42], data assimilation into numerical models [43-46], trajectory forecasts [47], and search and rescue [48].

HFR ocean data quality is affected by several factors such as geometric dilution of precision (GDOP) and signal-to-noise ratio (SNR) [49]. In order to quantitatively assess radar data quality for this case, a commonly used evaluation index, GDOP, describes the quality of a velocity measurement based on the geometrical arrangement between the radar stations and the location being monitored 
that had been used to assess velocity components. A low value of GDOP indicates ideal geometry and higher values indicate poor geometry where the two velocity components are not highly resolved [50]. O'Donncha, et al. [51] found that the meridional component of surface current flow along the baseline is distorted most by GDOP in Galway Bay, while the zonal component is more accurately resolved, apart from a very small domain along the shoreline due to a slight rotation of the baseline from east-west. Additionally, Ren, et al. [43] compared radial currents between the radar data and ADCP data in the study domain, and found that modest correlation existed between the two datasets.

Two SeaSonde Coastal Ocean Dynamics Applications Radar (CODAR) radars were deployed intermittently at Galway Bay to monitor surface currents and waves since the summer of 2011 [52]. Radar stations are located at Mutton Island (C1 in Figure 1) and Spiddal Pier (C2 in Figure 1); the operating frequency is $25 \mathrm{MHz}$ at both stations. Radial current vector fields from each station are recorded every hour [53]. Data from both radars are routinely transmitted to a combination center that is located in the campus of National University of Ireland, Galway, Ireland. The radar postprocessing software system interpolates surface current data onto a standard orthogonal grid $300 \times 300 \mathrm{~m}$. Measurements of surface currents obtained with the HFR system in Galway Bay have been validated with ADCP data in detail by O'Donncha, et al. [51] and Ren, et al. [54]. The land-based HFR system has provided a powerful method of obtaining synoptic monitoring of surface currents with high temporal and spatial resolutions. Identification of synoptic characteristics of surface flows is a meaningful approach for obtaining good insights into both internal dynamic processes and variations of ocean surface movement.

Coverage of surface currents captured by the HFR system varies in space and time due to variability of the ocean surface roughness. An EOF analysis is consistent and reliable when there are no spatial gaps in the datasets; thus, HFR data with high coverage density in space and time were selected and used in the research. The HFR data at 1117 spatial points between Julian day 220 and Julian day 232,2013 , were used in the following analysis. Because it is the first time that surface currents were obtained at high temporal and spatial resolution using a model and radar system in the study domain, analysis of these short-term (thirteen day) dataset using SOM and EOF can be viewed as a test.

\subsection{Numerical Model}

The coastal model Environmental Fluid Dynamics Code (EFDC) was applied to simulate the hydrodynamics of Galway Bay. EFDC was developed at the Virginia Institute of Marine Science by the U.S. Environmental Protection Agency (EPA) [55,56]. As a free open source numerical model, EFDC reduces the access threshold for users. EFDC consists of four linked modules: hydrodynamic, water quality and eutrophication, sediment transport, and toxic chemical transport and fate. Only the hydrodynamic module was used to simulate surface flows in this research. This module solves the three-dimensional, vertically hydrostatic, free surface, turbulent averaged equations of motions for a variable density fluid. The hydrodynamic component of EFDC implements a semi-implicit, conservative finite volume solution scheme for the hydrostatic primitive equations with either twoor three-level time stepping [55-57]. The model uses orthogonal curvilinear coordinate or Cartesian rectangular coordinate system and structured grid horizontally, which is suitable for long and straight shoreline with shorter calculation time. The sigma coordinate system is used vertically to avoid the precision difference between deep water area and shallow water area. Additionally, EFDC can simulate one-dimensional, two-dimensional, and three-dimensional hydrodynamic force and water quality of water body. The internal and external mode splitting method is used in the calculation process, and the calculation accuracy of space and time is second order. The model has been successfully applied to a number of modeling studies of rivers, lakes, estuaries, and coastal regions [58-60]. Boas, et al. [61] compared EFDC with WASP (water quality analysis simulation program) and the commercially available software MIKE, and found that because the horizontal scale of most surface water is much larger than the vertical scale, in order to simplify the calculation, the vertical pressure gradient is regarded as the balance with buoyancy, and the vertical acceleration is ignored in EFDC, so EFDC is 
mostly used in shallow water areas. EFDC has a robust flooding and drying routine which is required in coastal regions. The structured grid also leads to the low adaptation of EFDC to the curved coastline. For these reasons, EFDC was applied to Galway Bay.

A 3D hydrodynamic model of Galway Bay (see Figure 1) was developed using a regular grid coordinate system; a spatial resolution by $150 \mathrm{~m}$ in both horizontal directions was employed generating $380 \times 241$ grid cells in this research. A bathymetric model of Galway Bay was developed from the recent, high resolution Integrated Mapping for the Sustainable Development of Ireland's Marine Resource (INFOMAR) seabed data program. Variable vertical layer thicknesses were used in the model with a thinner layer at the top and bottom of the water column and thicker layers in the middle, thereby ensuring that wind forcing was not overly damped by tidal forcing. A detailed description on setting up vertical layer structure for the Galway Bay was reported by Ren, et al. [54]. The meteorological forcing parameters including wind, pressure, rainfall, solar radiation, and relative humidity were obtained at a one-minute interval from the Informatics Research Unit for Sustainable Engineering (IRUSE) weather station approximately $5 \mathrm{~km}$ from station C2 (see Figure 1). Records of the River Corrib inflows entering Galway Bay close to the north of point C2 were obtained from the Irish Office of Public Works (OPW). Tidal water elevation time series generated from Oregon State University Tidal Inversion Software (OTIS) were used to define the tidal forcing at the western and southern open boundaries in the model $[62,63]$.

\subsection{Self-Organizing Map}

Kohonen self-organizing maps or self-organizing maps are a type of neural network algorithm proposed by Tuevo Kohonen [64]. The SOM is a kind of unsupervised learning algorithm, which captures patterns in the input data through competitive learning, hence the name "self-organizing". SOM retains a principal "features map" of the input data; this makes SOM very useful. SOM is also considered a "map" projection method. Another intrinsic characteristic of SOM is that vector quantization, which reduces multidimensional data into lower dimensional spaces (usually one or two dimensions), is easier to understand. Additionally, SOM builds relationships that retain information so that any topological relationships developed within the training set are maintained.

Figure 2 presents an example of a $4 \times 3 \mathrm{SOM}$ structure. $X_{1}, X_{2}, \ldots, X_{n}$ are input data, i.e., the two-dimensional surface flow fields in this research, which are projected to each node in the output layer. $X_{i}$ contains surface velocity components having $I$ data points and $J$ data points in the $\mathrm{x}$ and $\mathrm{y}$ directions, respectively, over the analysis domain. This indicates that each node of an output layer is linked to each input dataset. Each node of an output layer, as shown in Figure 2, has a specific topological position and contains a vector of weights of the same dimension as the input vectors. If the training data consists of vector $X$ of $n$ dimensions, each node contains a corresponding weight vector of $n$ dimensions. The dotted lines connecting the nodes at the output layer only represent adjacency and do not signify connectivity. There are no lateral connections among nodes on the output layer. The weight vectors adopt an alternative initialization scheme. As the input dataset is processed through the SOM neural network, the summed distance between weights and input dataset are computed at each node. In each successive step the weight vector of the unit having the smallest Euclidian distance is selected as the "winner," the best match unit (BMU) or codebook vectors [30]. The SOM is a neighborhood-preserving vector-quantitative analysis tool working on the winner-take-all rule in a mathematical sense, where the $B M U$ is determined as the most similar node to the input at an instant of time. The key of the SOM algorithm is to update the BMU and its neighborhood nodes concurrently. Input topology of dataset is preserved on the output nodes through performance of such a mapping [65]. Details of the implementation procedure of SOM are described in the Appendix A.

Advantages of the SOM method can be listed as follows: (a) an intuitive approach to building customer segmentation profiles, (b) simple and easy to explain results, and (c) new data points can be mapped to the trained model for predictive purposes. To quantitatively assess the mapping quality, two measures are used. The first is the quantization error ( $Q E$, see details in Appendix A), which is used 
as a metric of the average distance between each data vector and the $B M U$, whose weight vector has the minimum distance. The second measure is the topographic error (TE, see details in Appendix A), which represents the proportion of all data vectors for which the first and second BMUs are not adjacent to each other [66]. Lower values of $Q E$ and TE indicate better reproduction of the patterns of the SOM model. A batch algorithm, a rectangular-lattice structure with a sheet map and the "ep" neighboring function for SOM analysis, as recommended by Liu, et al. [23] and Vilibić, et al. [67], were used in this research.

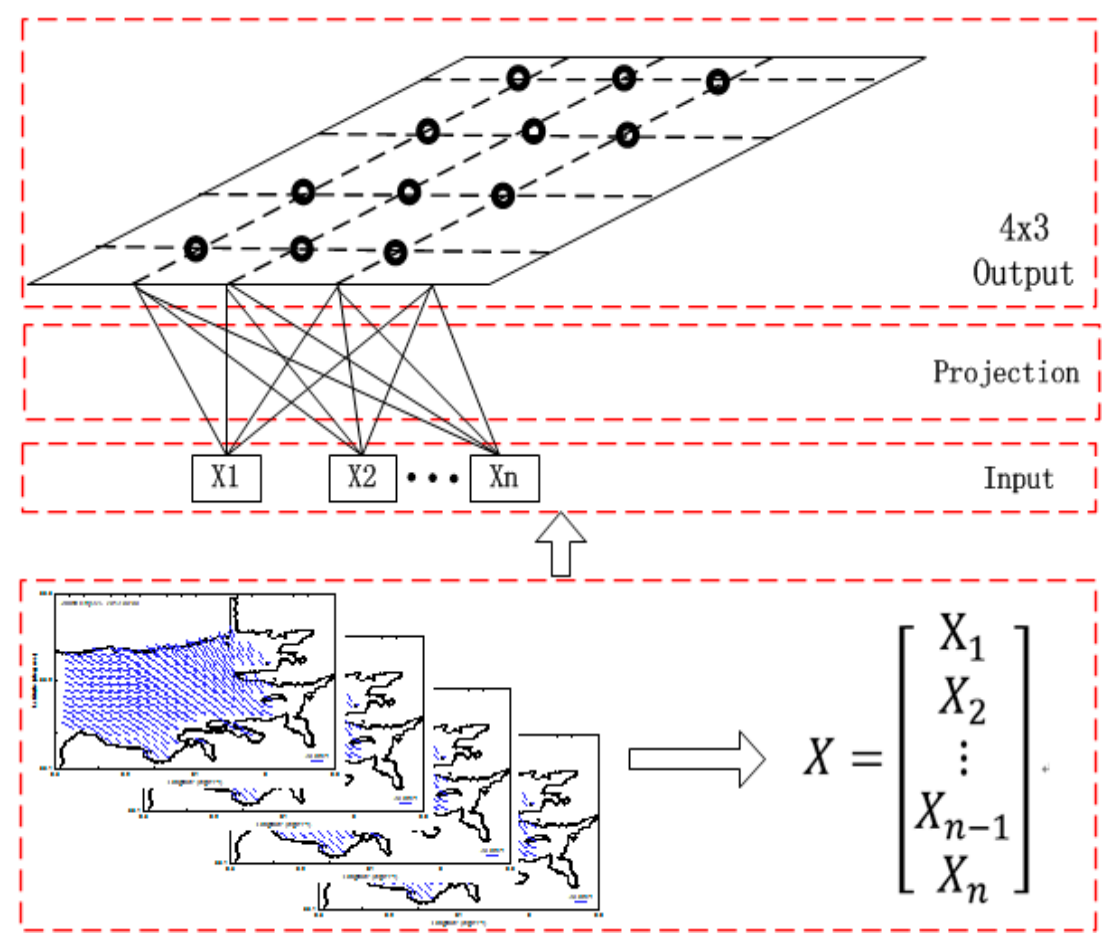

Figure 2. Architecture of a $4 \times 3$ self-organizing map (SOM) network.

\subsection{Empirical Orthogonal Function}

An empirical orthogonal function analysis is a data decomposition tool and it can be used to explain original data in the form of a series of orthogonal base functions with associated coefficients. EOF modes preserve the majority of the variations as much as possible through reducing the dimensionality of an original dataset. One unique attribute of an EOF analysis is that EOF base functions are derived from the original dataset through decomposition. This produces EOF modes that preserve the inherent characteristics of the original dataset and converge rapidly [68]. A detailed description about the EOF analysis method can be found in Hannachi, et al. [69] and Monahan, et al. [70]. In this research, for given vector fields of surface currents in Galway Bay, an investigation of spatial-temporal variations of surface flows was implemented by EOF decomposition. Details of EOF analysis are presented in the Appendix A.

\section{Results}

Since coverage of HFR surface currents varied in space and time and to ensure reliable analysis in this research, surface currents only at points always covered by the HFR system during the analysis period were selected and used in the following analysis. Here, 312-h surface vector fields with 1117 observation points in total for Galway Bay were used for both SOM and EOF analyses. Surface vector fields extracted from model results at the same points were used. Both observed and simulated surface vector field datasets contained 2234 (1117 for both $\mathrm{u}$ and $\mathrm{v}$ components) columns and 312 rows. 


\subsection{SOM Analysis}

The goal of the SOM technique is to partition an incoming dataset of arbitrary dimension into a two-dimensional discrete feature map and to display this transformation adaptively in a topologically ordered fashion. Extracted SOM patterns are arranged in a two-dimensional array such that similar patterns are located nearby and dissimilar patterns are distant [71]. To completely represent the characteristic surface flow features and make it small enough for visualization and interpretation, after several test runs, a commonly used SOM size of $4 \times 3$ was selected and used in this research.

\subsubsection{Spatial Variability}

The batch of surface flow fields for both model results and HFR data were characterized into 12 typical SOM patterns with corresponding frequencies of occurrence. The $4 \times 3 \mathrm{SOM}$ array results of model results and HFR data are shown in Figures 3 and 4, respectively. To quantify the representation of each SOM pattern, the frequency of occurrence of each SOM pattern was computed by summing the number of the $B M U$ by the total record lengths (the number of input vectors, 312 here), see details in Appendix B. The relative occurrence frequency for corresponding SOM patterns is shown in the upper left corner in Figures 3 and 4.

(a)

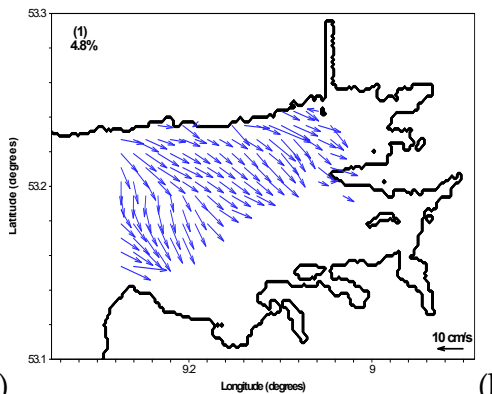

(b)

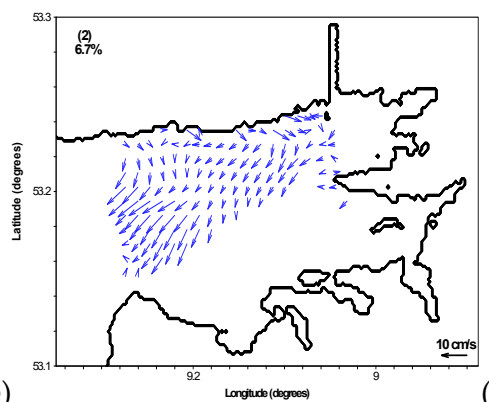

(c)

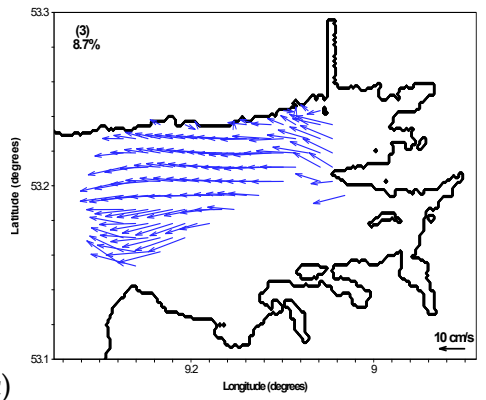

(e)

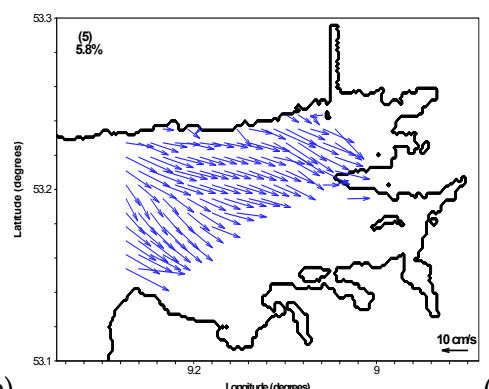

(f)

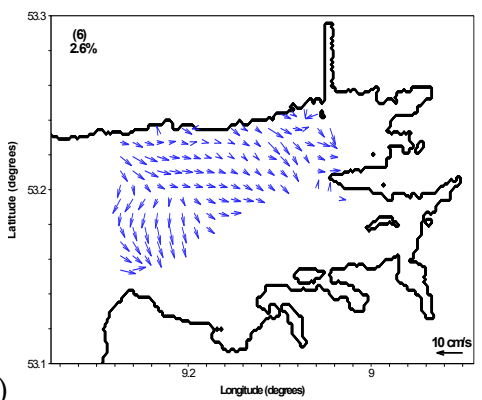

(d)

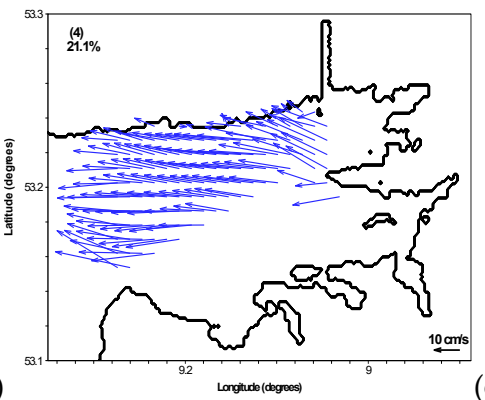

(g)

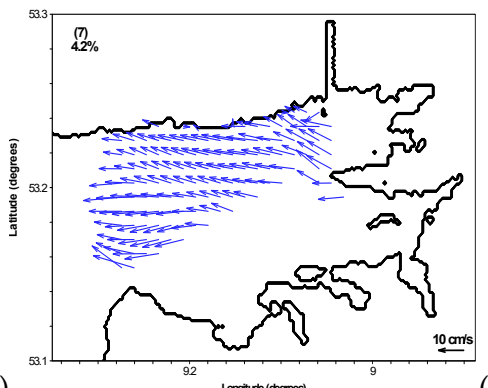

(h)

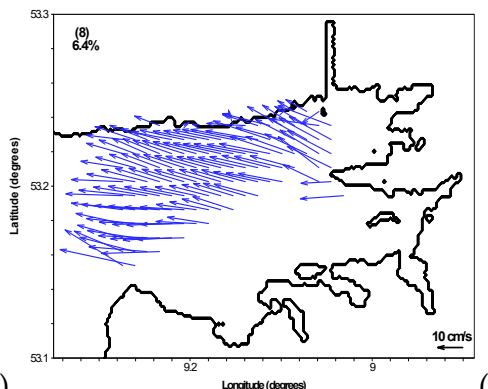

(i)

Figure 3. Cont.

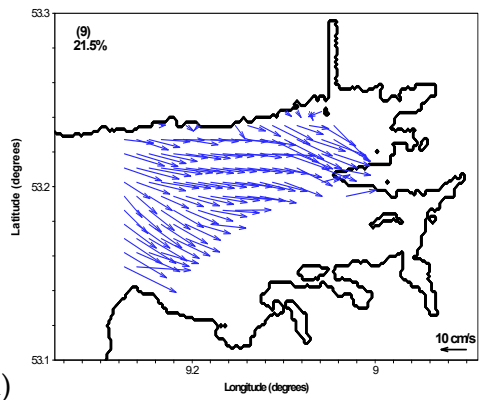




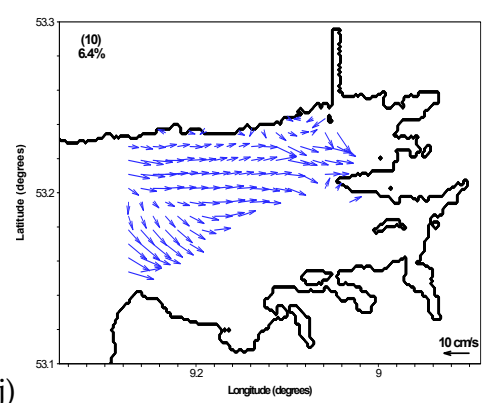

(k)

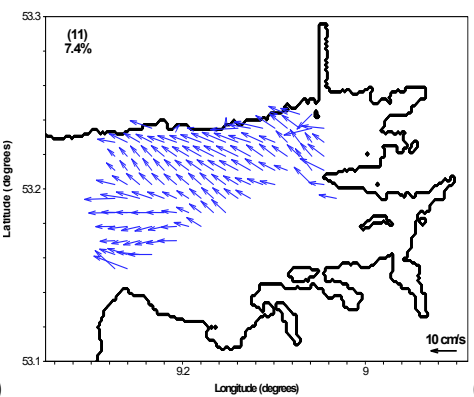

(1)

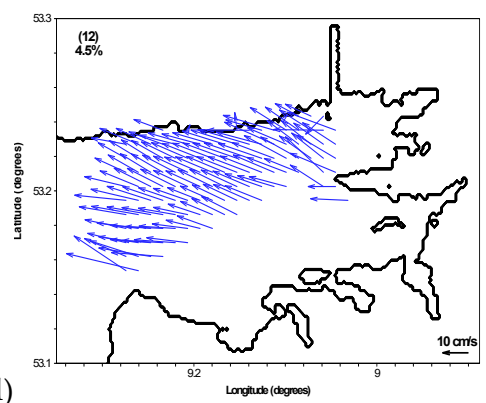

Figure 3. Characteristic spatial patterns of surface currents from model results extracted by a $4 \times 3 \mathrm{SOM}$ analysis (subfigures (a-1) indicates twelve spatial SOM patterns, respectively; the occurrence frequency is given as a percentage number for each pattern at the topleft).

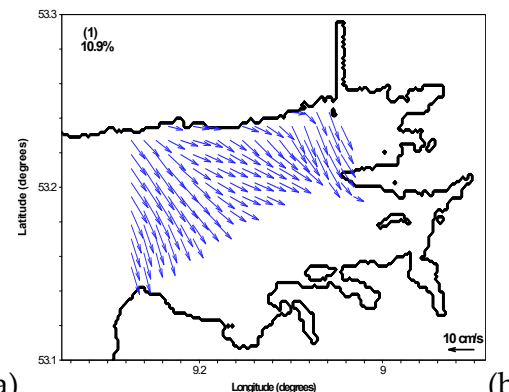

(a)

(d)

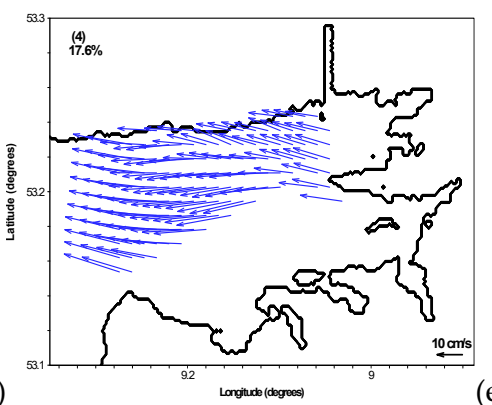

(e)

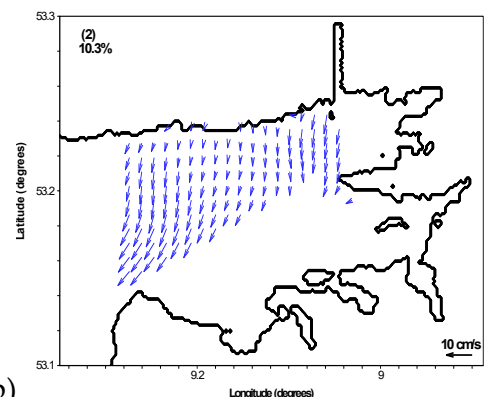

(b)

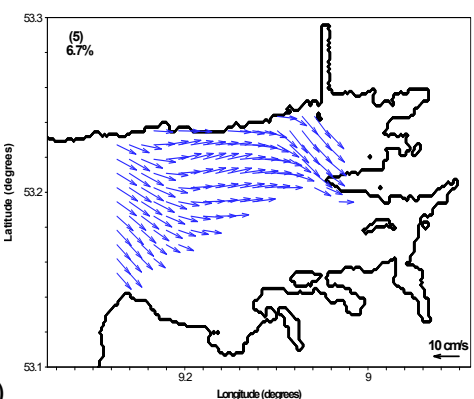

(f)

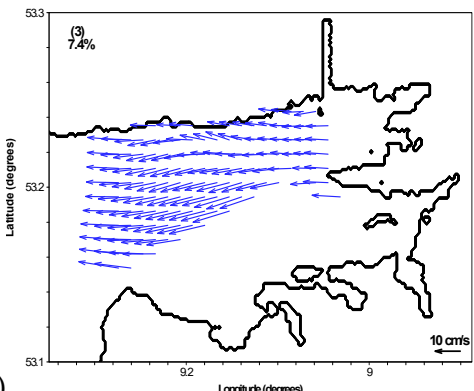

(c) (g)

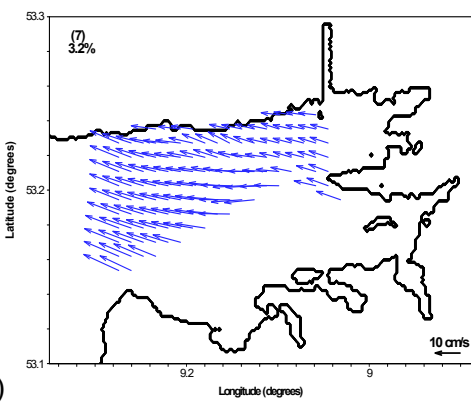

(h)

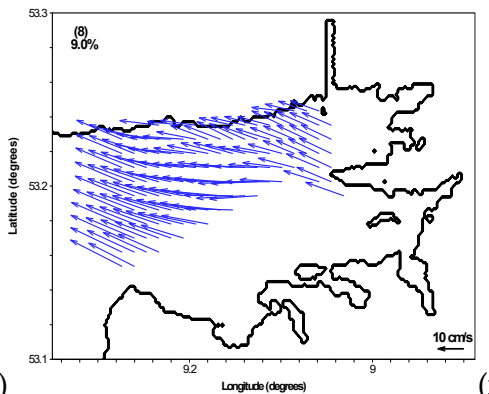

Figure 4. Cont.
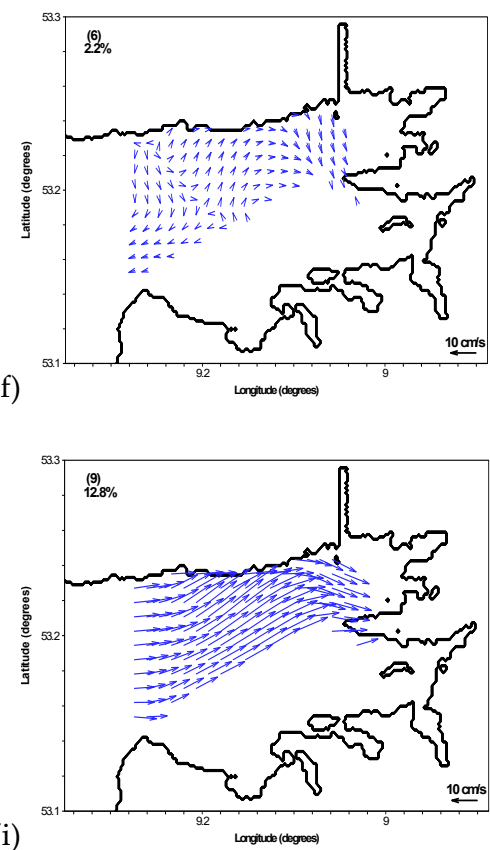

(i) 


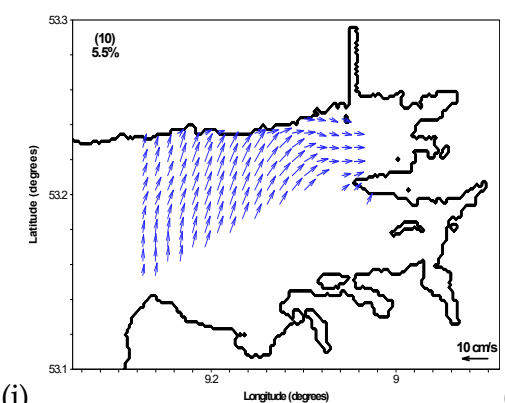

(j)

(k)

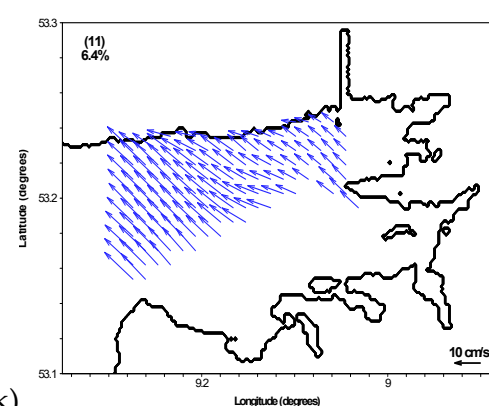

(1)

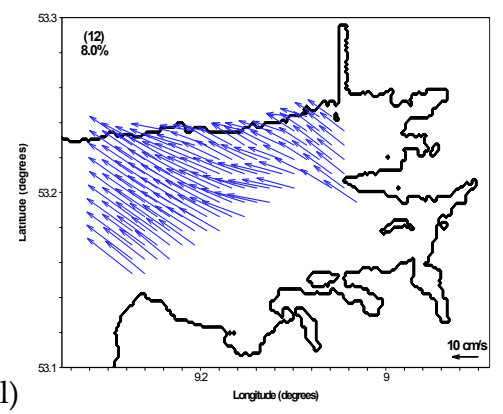

Figure 4. Characteristic spatial patterns of surface currents from radar extracted by a $4 \times 3 \mathrm{SOM}$ analysis (subfigures (a-1) indicates twelve spatial SOM patterns, respectively; the occurrence frequency is given as a percentage number for each pattern at the topleft).

For SOM surface flow patterns as shown in Figure 3, twelve SOM patterns can be categorized visually into four groups, as presented in Table 1.

Table 1. Categories of SOM patterns for model results.

\begin{tabular}{cccc}
\hline Group & SOM & Representative Characteristics & Total Occurrence Frequency (\%) \\
\hline 1 & $1 / 5 / 6 / 9 / 10$ & southeastward and eastward flows & 41.1 \\
2 & $3 / 4 / 7 / 8$, & western flows & 40.4 \\
3 & $11 / 12$ & northwestward flows & 11.9 \\
4 & 2 & southwestward and alongshore flows & 6.7 \\
\hline
\end{tabular}

Table 1 shows that the occurrence frequency of group 1 consisting of four SOM patterns (1/5/6/9/10) was the highest at $41.1 \%$ with southeastward and eastern flows. Surface flow fields categorized as group 2 had the second highest occurrence frequency with westward flows. The total occurrence frequency of groups 1 and 2 was greater than $81 \%$. This indicates that the main patterns of surface flows were southeastern and alongshore flows during the analysis period. Group 3 with an occurrence frequency greater than $11 \%$ had a northwestward trend for surface flows. At $6.7 \%$, the occurrence frequency of group 4 was much smaller than groups 1-3. This indicates that SOM pattern 2 occurred with relatively low probability. Additionally, magnitudes of surface flows in SOM pattern 2 were smaller than that of other SOM patterns.

For surface flows of HFR data, twelve SOM patterns can be categorized visually into six groups, as presented in Table 2. Table 2 shows that four SOM modes (3/4/7/8) of surface flows were categorized as group 1 with the highest occurrence frequency at 37.2\%. Occurrence frequencies for groups 2, 3, 4, and 6 were greater than $10 \%$, whereas the total occurrence frequency of group 5 was quite low, at $2.2 \%$.

Table 2. Categories of SOM patterns for high frequency radar (HFR) data.

\begin{tabular}{cccc}
\hline Group & $\begin{array}{c}\text { SOM } \\
\text { Pattern }\end{array}$ & $\begin{array}{c}\text { Representative Characteristics of Surface Vector } \\
\text { Fields }\end{array}$ & Occurrence Frequency (\%) \\
\hline 1 & $3 / 4 / 7 / 8$ & western flows & 37.2 \\
2 & $1 / 5$ & southeastward and alongshore flows & 17.6 \\
3 & $9 / 10$ & northeastward and alongshore flows & 18.3 \\
4 & 2 & southern and southwestward flows & 10.3 \\
5 & 6 & southwestward and northeastward flows & 2.2 \\
6 & $11 / 12$ & northwestward flows & 14.4 \\
\hline
\end{tabular}

Coastal currents in Galway Bay are mainly driven by tides and winds. Tides typically propagate in western and eastern directions corresponding to tidal flooding and ebbing, respectively. Figure 3 shows that western currents existed in group 2 by total occurrence frequency 40.4\%; eastern currents (patterns 9 and 10) existed in group 1 by total occurrence frequency $27.9 \%$. Surface currents of model results 
during tidal flooding were stronger than during tidal ebbing. However, SOM patterns having eastern and western current patterns in the radar data were different. Figure 4 shows that eastern currents existed in SOM patterns 5 and 9 by total occurrence frequency $19.5 \%$ for radar data; western currents existed in group 1 by total occurrence frequency $37.2 \%$. Surface currents of radar data during tidal ebbing were stronger than during tidal flooding. Since spatially constant winds were used in the modeling, the difference in eastern and western SOM current patterns between model results and radar data may be due to influences of wind variation in space. Thus, wind roses and mean wind vectors based on European Centre for Medium-Range Weather Forecasts (ECMWF) data with $0.15^{\circ} \times 0.15^{\circ}$ spatial resolution and 6-h temporal resolution are presented in Figures 5 and 6 to further investigate effects of winds on SOM current patterns.

Figure 5 show that wind speeds and directions varied over the analysis domain. Moreover, occurrence frequencies of winds in the same direction were also different. In general, dominant winds blew from the ocean toward land during the analysis period. Figure 6 shows that the directions of mean wind vectors over higher latitude points had a clockwise trend, while the directions were more uniform (southwest) over lower latitude points. Considering SOM patterns of model results and radar data, group 3, as shown in Figure 3, with total occurrence frequency $11.9 \%$ had a northwestern current pattern from the model results; group 6 (SOM patterns 11 and 12) and SOM pattern 10 with total occurrence frequency $19.9 \%$ had a landward (northwestern, northern, and northeastern) current pattern in the radar data. The occurrence frequency of landward current patterns extracted by SOM analysis was stronger in the radar data than in the model results. This indicates that surface currents driven by winds were better captured by the radar observation system than the numerical model. As stated before, this is probably due to the fact that spatially constant winds were used in the model, and demonstrates the importance of wind forcing on surface hydrodynamics.

(a)

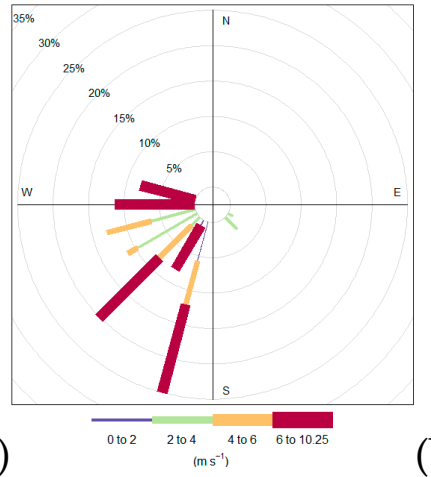

(b)

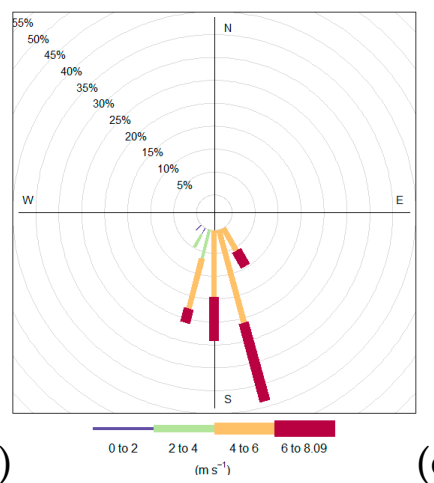

(c)
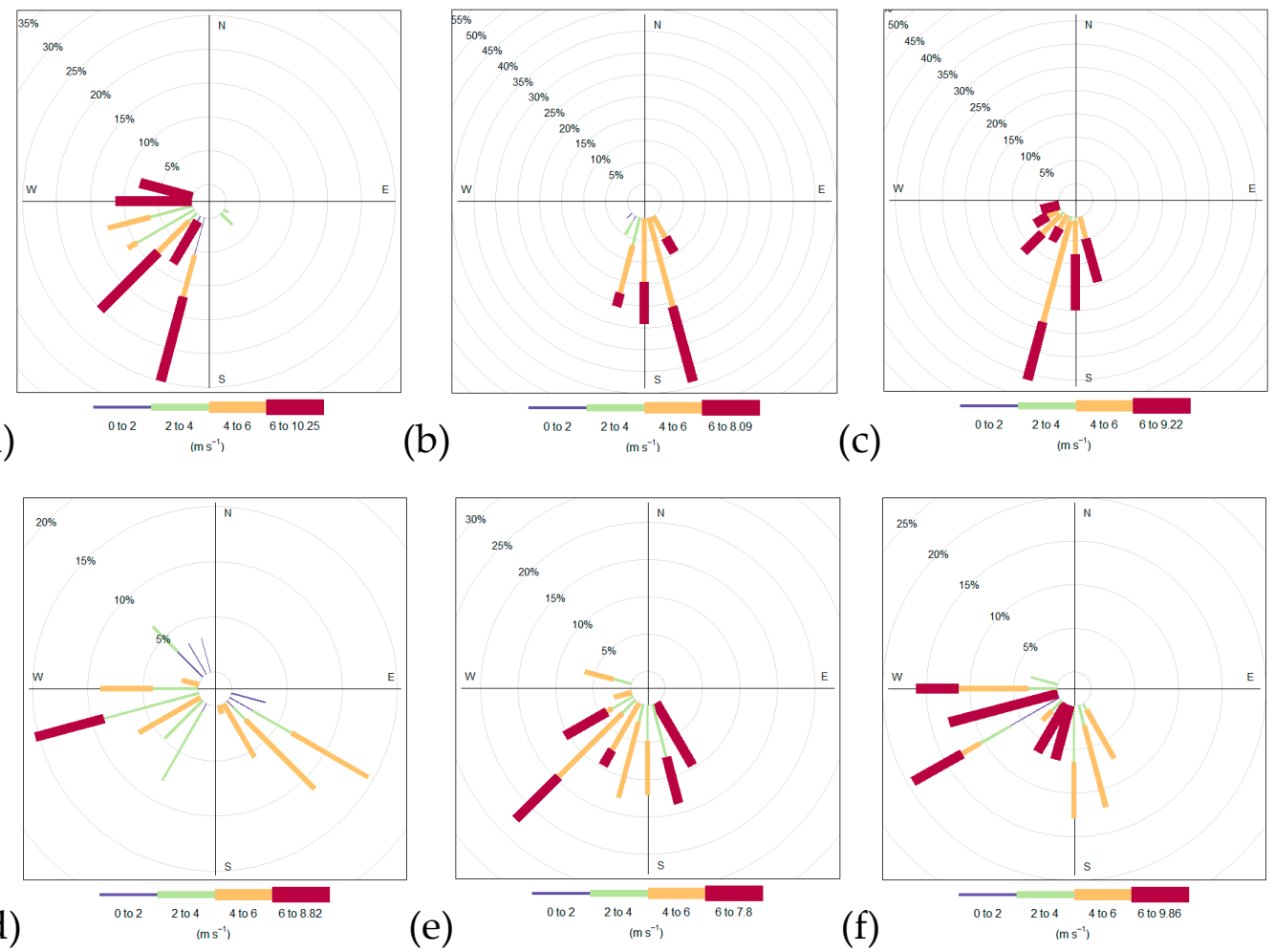

(e)

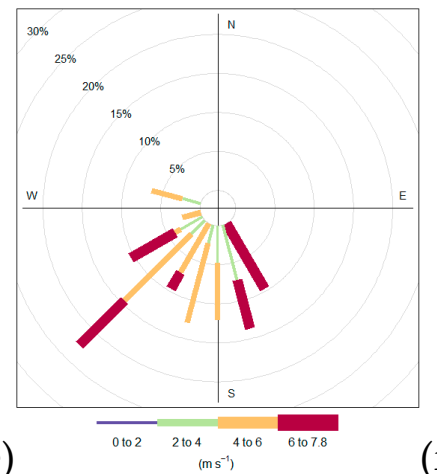

(f)

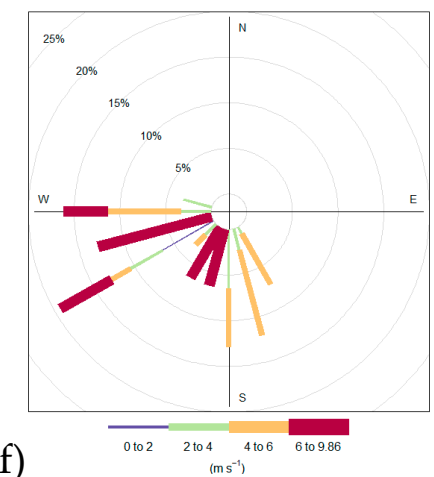

Figure 5. Wind roses during analysis period. (Locations of W1-W6 are shown in subfigures (a-f), respectively; direction indicates wind blowing from).

Additionally, infrequent winds blowing from land to ocean (W1, W4, and W5 in Figure 5) occurred during the analysis period. Corresponding vector patterns were also extracted by SOM for both 
model results and radar data. Southeastern currents, including SOM patterns 1, 5, and 6, had a 13.2\% occurrence frequency for model results; offshore SOM current patterns 1 and 5 had a 17.6\% occurrence frequency for radar data. In summary, SOM patterns accounting for the effects of tides and winds had occurrence frequencies of $97.8 \%$ and $93.3 \%$ for radar data and model results, respectively. This indicates that the SOM technique can extract representative synoptic characteristic patterns of surface flows. Additionally, the effects of the main driving forces (tide and wind) on surface flows can be well linked to SOM patterns, especially for the radar data.

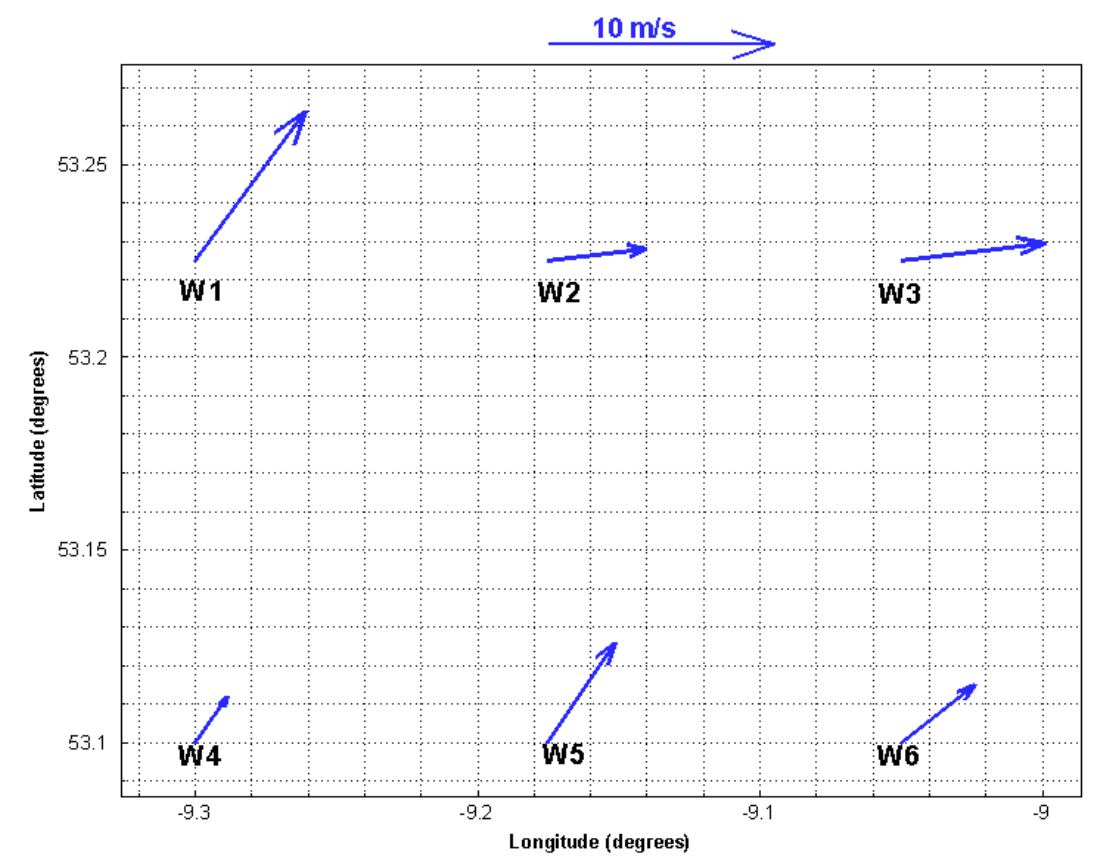

Figure 6. Mean ECMWF (European Centre for Medium-Range Weather Forecasts) wind vectors during analysis period.

\subsubsection{Temporal Evolution}

To analyze the evolution process of the SOM patterns in time, BMUs were computed and are shown in Figure 7. A BMU can be found for each input data vector by comparing the 12 SOM patterns with the input data map.

Figure 7a shows that the evolution of $B M U$ for model results generally had two patterns: (I) $12 \rightarrow$ $4 \rightarrow 2 \rightarrow 1 \rightarrow 9 \rightarrow 11$ and (II) $11 \rightarrow 8 \rightarrow 4 \rightarrow 3 \rightarrow 2 \rightarrow 1 \rightarrow 9 \rightarrow 10$. Evolution processes of both type I and II show that the general variation trend of surface flow fields was anticlockwise, i.e., westward $\rightarrow$ southwest $\rightarrow$ southeast $\rightarrow$ westward, as shown in Figure 3. The corresponding group category pattern is $2 \rightarrow 3 \rightarrow 1 \rightarrow 2$, as presented in Table 1 .

Figure $7 \mathrm{~b}$ shows that evolution of $B M U$ for HFR data was not as uniform as the model results. The evolution trend was $12 \rightarrow 8 \rightarrow 4 \rightarrow 3 \rightarrow 2 \rightarrow 1$. The trend of surface flow fields was generally anticlockwise, i.e., northwestward $\rightarrow$ westward $\rightarrow$ southward $\rightarrow$ southeastward, as shown in Figure 4 . The corresponding group category pattern was $6 \rightarrow 1 \rightarrow 4 \rightarrow 2$, as presented in Table 2 .

In general, a similar anticlockwise evolution trend changing from westward to southeastward existed for surface flow fields in both the model results and HFR data. However, the evolution trend of $B M U$ was more regular in the model results than in the HFR data. This is again probably due to the fact that a spatially constant wind was applied to force the surface boundary of the models. Thus, tide and wind were the same over simulated domain. However, surface currents monitored by the HFR system appear to have captured more information of surface currents driven from winds. 


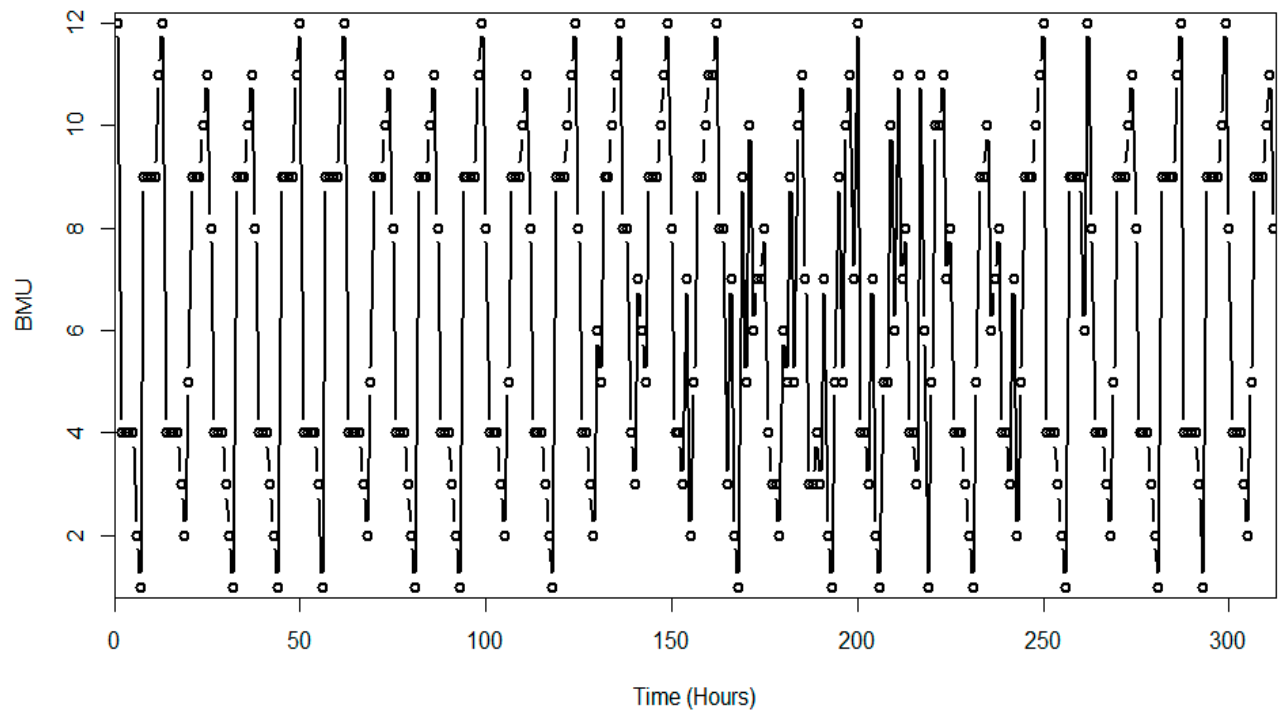

(a)

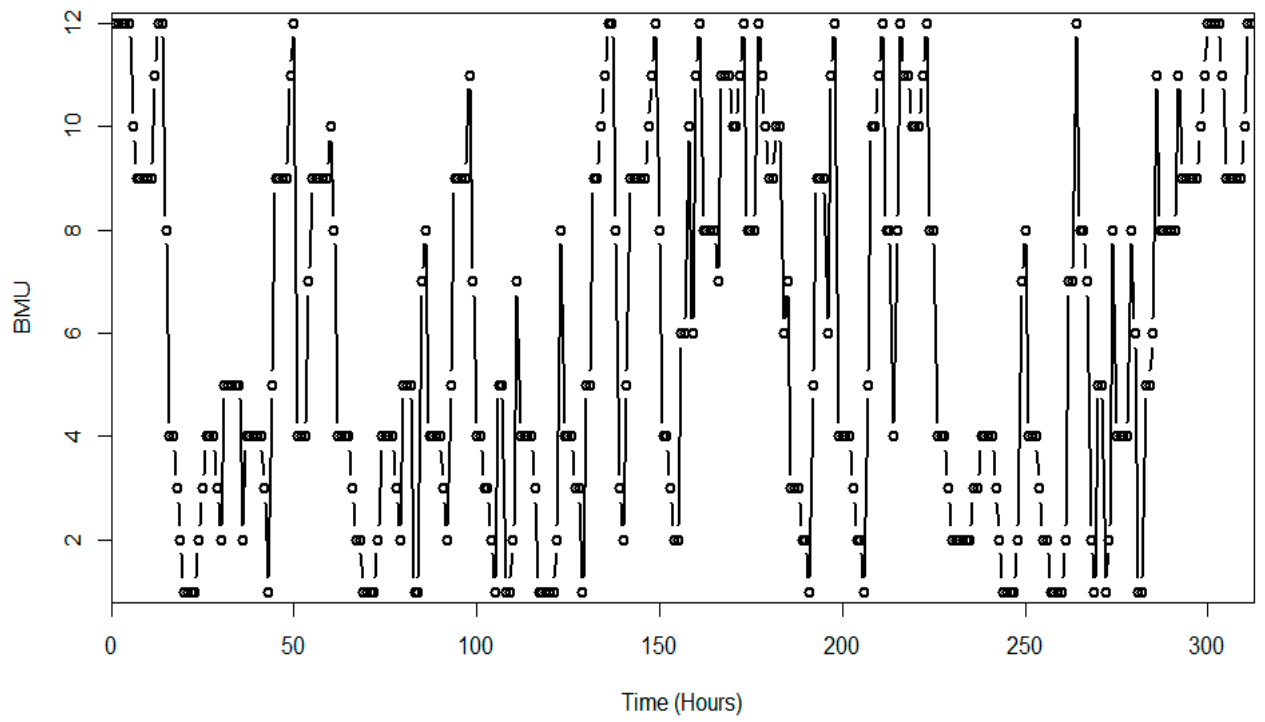

(b)

Figure 7. Time series of best match unit $(B M U)$ corresponding to 12 SOM patterns ((a) model results and (b) radar data).

\subsection{Empirical Orthogonal Function}

In order to further compare the HFR data and numerical results, an EOF analysis was performed. EOF analysis reduces data dimensionality and represents characteristics of each dataset in a few concise and typical patterns in both space and time. The same dataset as used in the above SOM analysis was used in the following EOF analysis.

\subsubsection{Spatial Modes}

To investigate synoptic characteristics of coastal flow patterns extracted by EOF, the first six EOF eigenvector modes for both EFDC model results and HFR data, as shown in Figures 8 and 9, respectively, 
account for more than $95 \%$ of the explained variances. Variances explained by the corresponding EOF mode are presented in the left-hand corner in each panel.

(a)
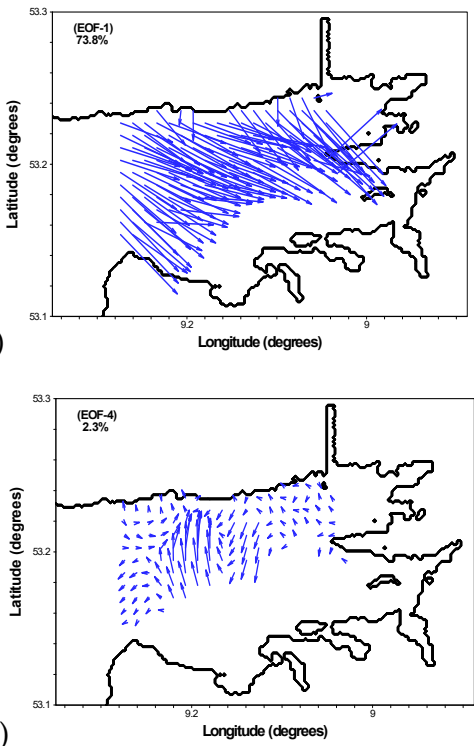

(b)
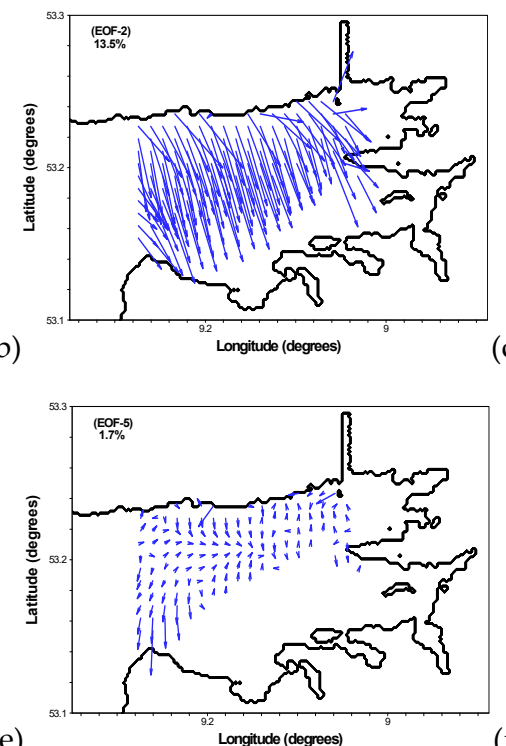

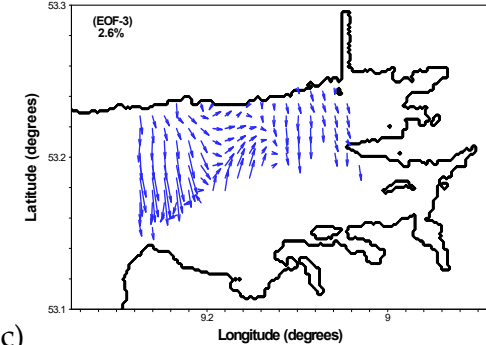

(c)

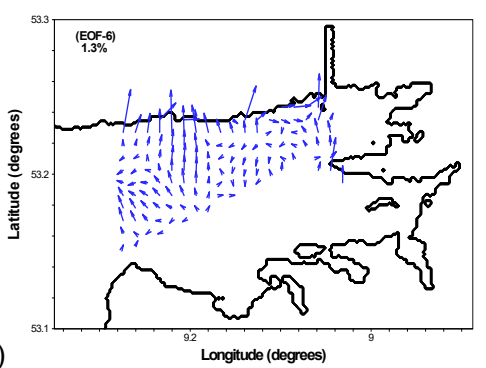

Figure 8. Spatial empirical orthogonal function (EOF) modes of model results (subfigures (a-f) indicates the first to the sixth EOF eigenvector modes, respectively).

(a)

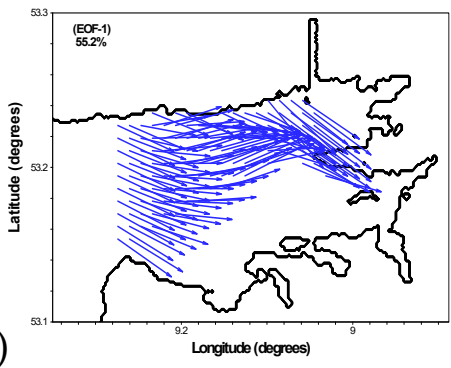

(b)

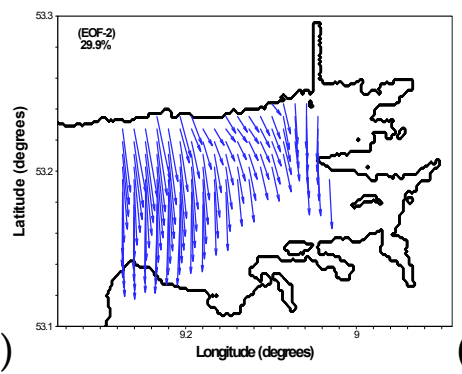

(c)
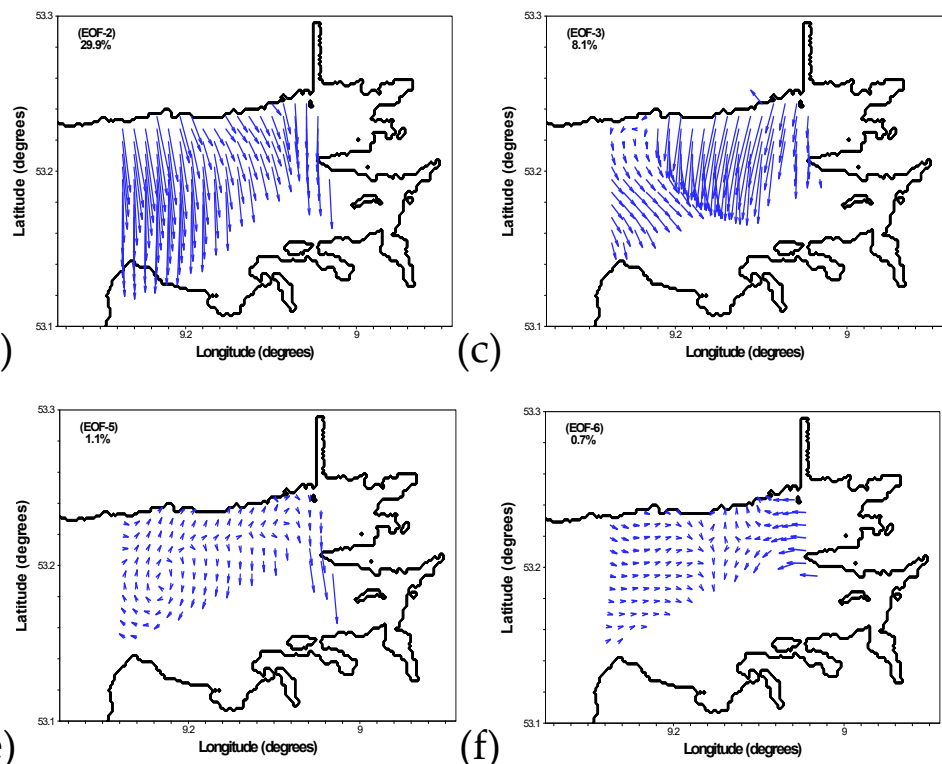

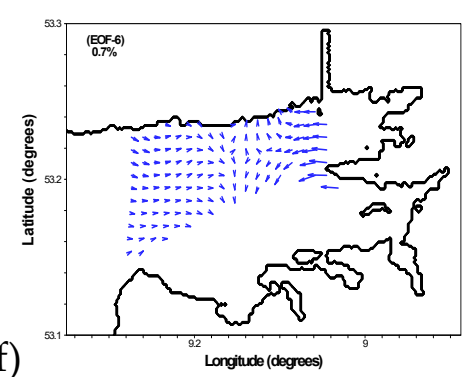

(d)

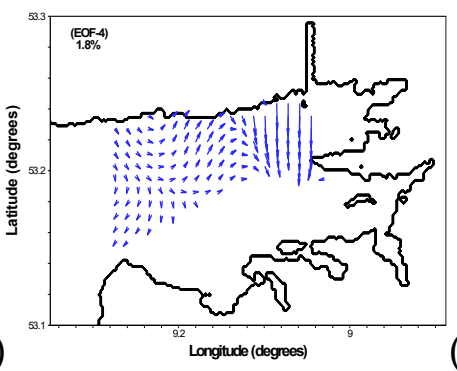

(e)
Figure 9. Spatial EOF modes of radar data (subfigures $(\mathbf{a}-\mathbf{f})$ indicates the first to the sixth EOF eigenvector modes, respectively).

The first EOF mode (EOF1) of the model results and the HFR data, as shown in Figures 8 and 9 , accounts for $73.8 \%$ and $55.2 \%$ of the variances separately. This indicates that the possibility of surface flow in EOF1 mode patterns for model results was larger than for HFR data. The general pattern of surface flows in EOF1 mode is southeast; while there are also alongshore surface flows in EOF1 mode of the HFR data. This may result from variation of winds in space, which was not captured by model.

The patterns of surface flows in EOF2 mode were more similar between model results and HFR data. The possibility of flow in EOF2 mode for the HFR data was greater than twice that of the model results. This indicates that patterns of surface currents in EOF2 mode were more likely to occur in 
the HFR data than in the model results, the trend of surface flows in this mode was in the northern direction. However, surface flow magnitudes of model results were larger than these of HFR data.

The differences of spatial patterns between model results and HFR data in EOF3 mode were more significant than in EOF1 and EOF2 modes. Spatial patterns in HFR data consisted of weak southeastward and strong southwestward flows, which converged around the $-45^{\circ}$ line. The general spatial pattern of surface currents for model results was southward; a northward trend of surface flows existed in the middle of area covered by the radar. Moreover, magnitudes of surface currents in EOF3 mode for the HFR data were larger than the model results.

Magnitudes of surface currents in EOF4 mode were small and similar between model results and HFR data. Disorder of spatial patterns exists in model results, while a southward trend exists across the right parts of displayed area. Surface flows bifurcate across the left parts with one in the southeastward direction and the other in the eastward direction in HFR data.

There was a clockwise and weak surface flow gyre in EOF5 mode in HFR data while the spatial pattern of EOF5 mode in the model results was generally disordered. Magnitudes of surface currents in this mode were small and comparable between the two datasets.

The spatial patterns of EOF6 mode in HFR data were generally offshore currents and along shore currents, but no such significant type of surface flow trend exists in model results. Additionally, magnitudes of surface currents near coasts were larger than other areas for model results, but magnitudes were generally uniform except for few large surface currents at the right corners for the HFR data.

The first two EOF modes accounting for the majority of the variance ( $>85 \%$ ) were relatively similar for model results and HFR data. The differences in the remaining four EOF modes between model results and HFR data were significant, but these modes accounted for a relatively small proportion of the variations.

\subsubsection{Variance of Surface Flows Explained by EOF Modes}

To further compare EOF analysis of model results and radar data, accumulative explained variances of the first 20 EOF modes and variance values of the first six EOF modes are presented in Figure 10 and Table 3, respectively. The value of variance represents the characteristic strength of the corresponding spatial EOF modes, as shown in Figures 8 and 9; this was computed relative to the entire set of EOF modes. A large value of variance indicates that the corresponding spatial EOF mode was significant; a small value of variance means that the corresponding spatial EOF mode was weak.

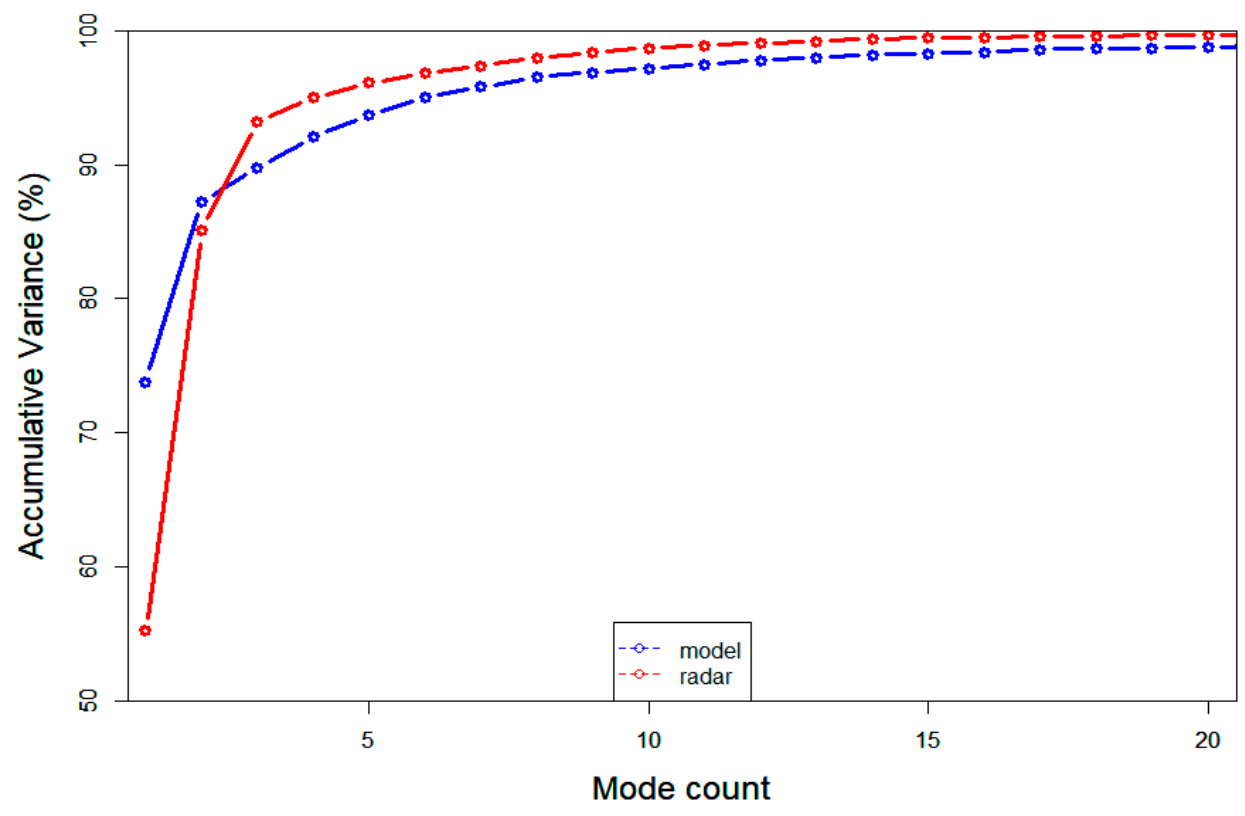

Figure 10. Variance of EOF modes. 
Table 3. Summary of variance for the first six EOF modes.

\begin{tabular}{ccccc}
\hline \multirow{2}{*}{ EOF Mode } & \multicolumn{2}{c}{ Variance (\%) } & \multicolumn{2}{c}{ Accumulative Variance (\%) } \\
\cline { 2 - 5 } & EFDC & HFR & EFDC & HFR \\
\hline 1 & 73.8 & 55.2 & 73.8 & 55.2 \\
2 & 13.5 & 29.9 & 87.2 & 85.1 \\
3 & 2.6 & 8.1 & 89.9 & 93.2 \\
4 & 2.3 & 1.8 & 92.1 & 95.0 \\
5 & 1.7 & 1.1 & 93.7 & 96.1 \\
6 & 1.3 & 0.7 & 95.0 & 96.8 \\
\hline
\end{tabular}

Note: EFDC and HFR indicate model results and high frequency radar dataset, respectively.

Figure 10 shows that the first two EOF modes explain the majority of variance for both model results and HFR data; accumulative variance of model results at $87.2 \%$ was greater than that of HFR data at $85.1 \%$. However, the accumulative variance of HFR data was greater than that of the model results from the third EOF mode. The accumulative variance explained by the first four EOF modes was greater than $90 \%$ for both model results and HFR data. This indicates that dominant patterns of surface flow fields can be well represented by only a few EOF modes. Variations of accumulative variances were not significant from the tenth EOF mode onward.

Although the difference of the variances in EOF1 mode between model results and HFR data was significant, the variance of the first two EOF modes (greater than $85 \%$ ), as presented in Table 3 , was comparable. The explained variance from the third EOF mode was much smaller than that of the first and second EOF modes. Additionally, the first six EOF modes accounted for greater than $95 \%$ of the total variance for both datasets. This indicated that the first six spatial EOF patterns represented synoptic characteristics of surface currents.

Figure 11 shows the first three EOF PCs over time for both model results and HFR data. A PC represents the time-varying characteristics (i.e., amplitudes) of the corresponding EOF eigenvector spatial distribution modes. The sign of the PC values determines the direction of EOF modes. Positive PC values indicate the same direction as the mode, while negative values indicate the opposite direction. The larger the absolute value of a particular PC, the stronger that PC EOF mode is at that moment. Time series of PC1 and PC2 for both model results and radar data exhibited cyclical trends with periods similar to a tidal period. The correlations between model results and HFR data of the first (PC1) and second PC patterns (PC2) are 0.80 and 0.58 , respectively. This indicates that model results and HFR data had high and moderate correlation, respectively, based on categories proposed by Taylor [72]. PC3 represents high frequency wind generated flows. However, correlation between the third principal components (PC3) was quite weak at 0.02 . This discrepancy is again due to limitations of the model to generate wind effects at short scales on the surface velocity fields, which would be a consequence of the wind field configuration which forces the model, similar to those obtained by Soto-Navarro, et al. [10].

To provide better insight into the temporal variation characteristics of the EOF PCs between model results and radar data, a spectral analysis was carried out on each EOF PC time series, see Figure 12. The EOF PC1 spectral density peaks were similar for model results and radar data (see Figure 12a), the corresponding frequency is $0.08 \mathrm{cph}$ (cycles per hour). This indicates that the semidiurnal signal $(12.5 \mathrm{~h})$ was strongest in both datasets, corresponding to the tidal frequency. However, for EOF PC2 and $\mathrm{PC} 2$, the spectral density trends were not as strong between the two datasets. The spectral density peaks of the radar data were weaker in PC2 and PC3 than that in PC1, while the spectral density peaks of the model results were much weaker in PC3 than PC1 and that in PC2. The differences may again result from the radar-derived surface current dataset containing spatially varying wind effects. 

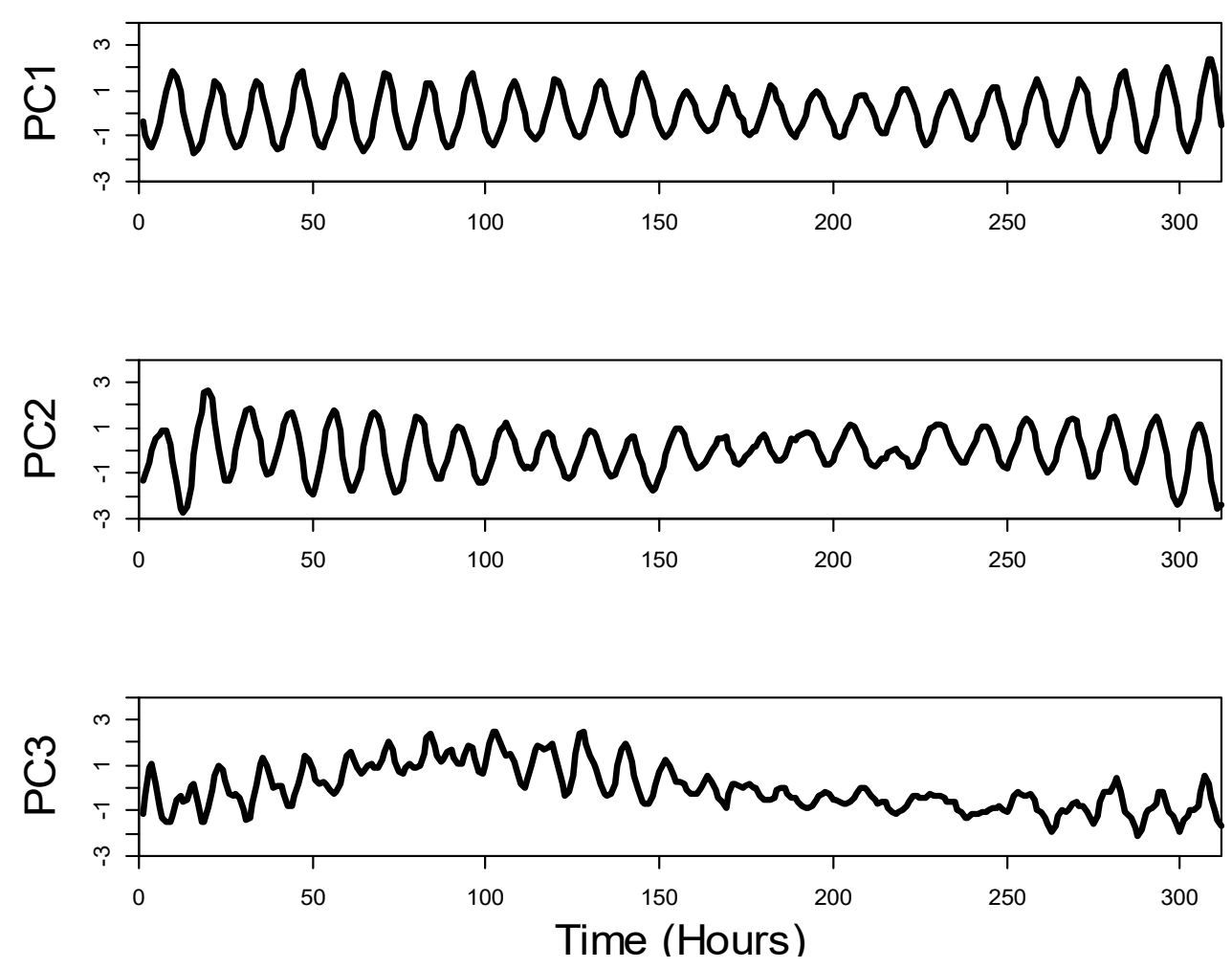

(a)
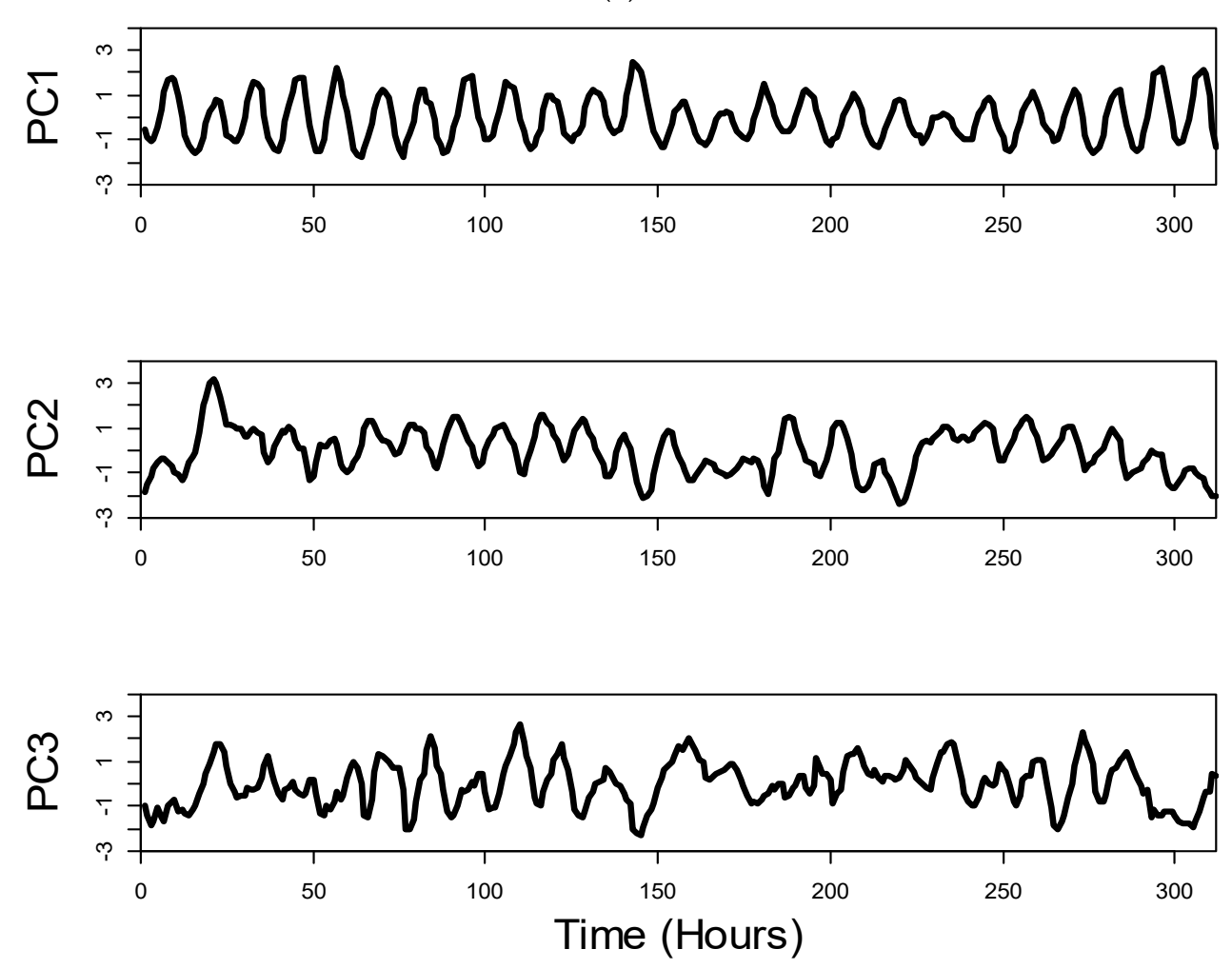

(b)

Figure 11. The first three EOF principal components (PCs): (a) model results and (b) HFR data. 


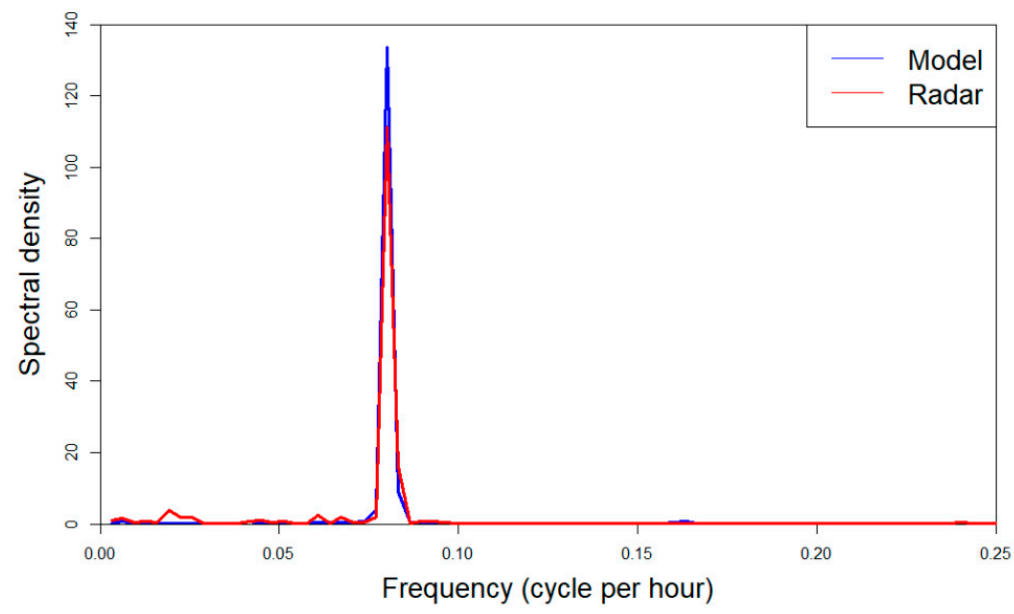

(a)

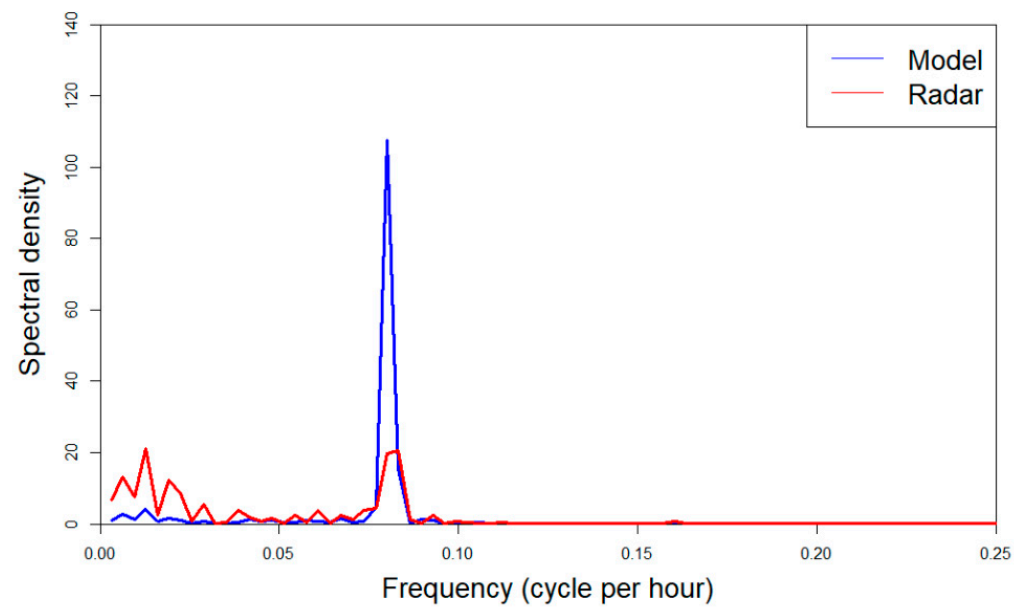

(b)

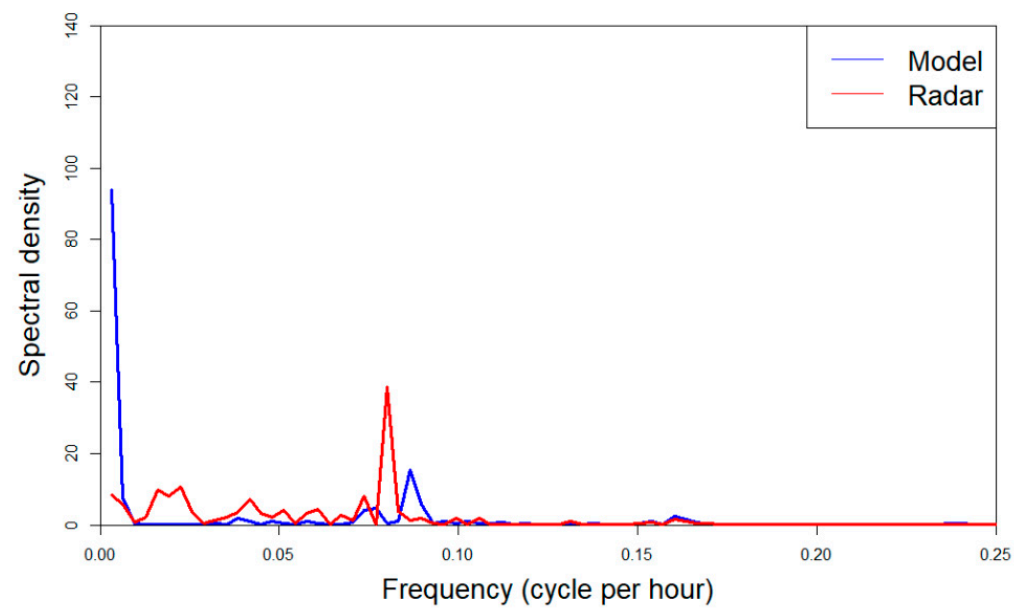

(c)

Figure 12. Spectral analysis of EOF PCs between model results and radar data $((\mathbf{a}-\mathbf{c})$ indicate spectral analysis for EOF PC1, PC2, and PC3, respectively). 


\section{Discussion}

Characteristic patterns of coastal flows were extracted by SOM (Figures 3 and 4) and EOF (Figures 8 and 9) for both model results and radar data. As stated in the introduction, the SOM technique has more advantages than other conventional data analysis techniques. Based on the SOM analysis, synoptic characteristic patterns of coastal flows were visualized. Additionally, time series of $B M U$ can offer evolution trends of characteristic patterns over space; this can better explain spatiotemporal variation of coastal flows. EOF technique can decompose coastal flow fields that change with time into two parts: the spatial modes which are constant in time and the time components (PCs), depending only on time. Although the EOF technique can extract synoptic characteristic patterns of coastal flows for both model results and radar data, it does not offer temporal variation trends corresponding to synoptic characteristic patterns over space. Since EOF is a linear decomposition technique, synoptic characteristics of coastal flow fields in space were less uniform than synoptic patterns extracted by the nonlinear SOM technique. In short, both SOM and EOF techniques offer synoptic characteristic patterns of coastal flow fields for both model results and radar data. However, more detailed information of variation properties for analysis dataset can be provided by an SOM analysis than that of an EOF analysis.

\section{Conclusions}

This paper presented SOM and EOF analyses of characteristics of surface flow fields in Galway Bay based on data provided by a HFR radar system and output from a numerical model. The main conclusions from this research follow.

Surface flows were categorized into four and six representative synoptic characteristic groups for model results and HFR data using SOM, respectively. The BMU time series indicate that the evolution of SOM patterns between model results and HFR data had similar trends varying from west to southeast in the anticlockwise direction.

The total variance explained by the first two EOF modes was comparable, with $87.3 \%$ and $85.1 \%$ for model results and HFR data, respectively, which underlines the agreement of both datasets in describing the general hydrodynamic characteristics of surface vectors in the region. The difference in the rest of the EOF modes, with relatively low variance, probably results from application of spatially constant wind in model.

Representative synoptic patterns of coastal surface flows were extracted using both EOF and SOM techniques. More detailed spatiotemporal information about coastal flow variation properties can provided by patterns obtained from SOM than from an EOF analysis.

The accuracy of model outputs was also assessed in detail by SOM and EOF type analysis; these analyses illustrate which processes models are good at reproducing and which processes are not well-represented by a model. In this case, the analysis shows that the model does not reproduce wind induced currents well, and so the model must be improved in this regard by forcing the surface with spatially varying wind stresses or through assimilation of the HF radar-derived surface currents [73]. Additionally, flow is dominated by tidal processes and, therefore, 13 days of observations is significantly relevant to those processes. In order to capture multiple (meteorological) synoptic scale events, which would better illuminate the effect of wind forcing, analysis of a longer period using modest spatial filtering could be advantageous and will be included in future research. The use of spectral analysis is very informative when comparing time-varying data that has dominant frequency components in EOF analysis.

This research analyzed a relatively short temporal dataset as this dataset was complete and did not include synthetic data that would introduce further uncertainty into the already difficult intercomparisons. Future research will consider longer-term datasets complemented by gap-filling to give a synthetic continuous dataset; results will be compared with the research presented herein.

In summary, the results above reflect the capability of the EFDC model and HFR system to describe characteristics of surface vector fields of the Galway Bay area. Typical patterns of surface 
vector fields associating with $B M U$ time series can better describe the evolution of the process of surface vector fields. SOM analysis provides more detailed information than that provided by EOF analysis. Such SOM patterns may be useful in a variety of forecasting applications, such as oil spill treatment and search and rescue. Although these results are interesting and useful, and SOM and EOF analysis methods provide a powerful tool to diagnose ocean processes from different aspects, it is also of great significance to further investigate the underlying physical mechanisms such as wind influence in future studies.

SOM has significant potential for surface current forecasting since it is simpler than other techniques, such as data assimilation, and computational costs are much lower. Forecasting of coastal flows based on the SOM technique will be undertaken by the authors in future research.

Author Contributions: Methodology, L.R.; formal analysis, L.R. and N.C.; writing-original draft preparation, L.R. and Z.H.; writing-review and editing, L.R. and M.H.; supervision, M.H., funding acquisition, L.R. and Z.H. All authors have read and agreed to the published version of the manuscript.

Funding: This research was funded by a project from the National Natural Science Foundation of China (NSFC), grant number 51909290; the Science and Technology Program of Guangzhou, China, grant number 201904010430; the Basic Research Program of Sun Yat-sen University, grant number 76170-18841203; the Research and Development Plan in Key Areas in Guangdong Province, grant number 2020B1111020003 and the Joint Research Project: NSFC (51761135022), NWO (ALWSD.2016.026), and EPSRC (EP/R024537/1): Sustainable Deltas.

Acknowledgments: We would like to thank ECMWF for providing wind data and the University of Oregon for providing the OTIS tide prediction software.

Conflicts of Interest: The authors declare no conflict of interest.

\section{Appendix A. Self-Organizing Map}

In general, implementation process of SOM algorithm can be summarized as follows:

1. Determine the size and type of the map.

2. Initialize each node's weights $W_{i j}$ at random.

3. Select a vector at random from the training dataset and present to the network. The following Euclidean distance formula is calculated to assess the "best matching unit $(B M U)$ " between each node and all input dataset.

$$
D I_{j}=\sum_{i=0}^{n}\left(X_{i}-W_{i j}\right)^{2}
$$

where

$D I_{j}$ is the $j$ th distance from all input vector;

$X_{i}$ is the $i$ th input vector having $I$ data points and $J$ data points in $x$ and $y$ directions, respectively;

$W_{i j}$ is the $j$ th node's weight;

$n$ in the number of weights.

The $B M U$ of each node is found based on calculating which nodes' weights are most like the input vector $X$. The neighborhood function is taken by assuming to maximum when distance is zero. There are four types of neighborhood function available: "bubble", "gaussian", "cutgauss" and "ep":

$$
\Theta(t)\left\{\begin{array}{cc}
F\left(\sigma(t)-d_{c i}\right) & \text { bubble } \\
\exp \left(\frac{-d_{c i}^{2}}{2 \sigma(t)^{2}}\right) & \text { gaussian } \\
\exp \left(\frac{-d_{c i}^{2}}{2 \sigma(t)^{2}}\right) F\left(\sigma(t)-d_{c i}\right) & \text { cutgauss } \\
\max \left\{0,1,-\left(\sigma(t)-d_{c i}\right)^{2}\right\} & \text { ep }
\end{array}\right.
$$


where

$\sigma(t)$ is the neighborhood radius at time $t$;

$d_{c i}$ is the distance between map units $c$ and $i$ on the map grid;

$F$ is a step function:

$$
F(x)= \begin{cases}0 & (\text { if } x<0) \\ 1 & (\text { if } x \geq 0)\end{cases}
$$

Determine the radius of the neighborhood of the $B M U$ (the size of the neighborhood decreases with each iteration).

Tune weights of nodes within the radius of the $B M U$ to make them more like the input vector. The closer a node is to the $B M U$, the more its weights are altered.

$$
\begin{gathered}
W_{i}(t+1)=W_{i}(t)+\Theta(t) \times L(t) \times\left(I(t)-W_{i}(t)\right) \\
L(t)=L_{0} e^{\left(\frac{-t}{\lambda}\right)}
\end{gathered}
$$

where

$L(t)$ is the learning rate.

Repeat steps (A2)-(A5) for $\mathrm{N}$ iterations.

Three parameters-number of iterations, learning rate, and neighborhood radius-need to be determined. The quantization error $(Q E)$, i.e., average distance between each input data vector $X_{i}$ and its $B M U\left(u_{B M U}\right)$ can be expressed as:

$$
Q E=\sum_{i=1}^{N}\left\|X_{i}-u_{B M U}\right\|
$$

The topographic error (TE) being used to measure the topology preservation can be calculated by the following formula:

$$
T E=\frac{1}{N} \sum_{i=1}^{N} u_{B M U}\left(X_{i}\right)
$$

where $u_{B M U}\left(X_{i}\right)$ is 1 if the first and the second BMUs are not adjacent to each other, otherwise it is $u_{B M U}\left(X_{i}\right)=0$.

\section{Appendix B. Empirical Orthogonal Function}

In particular, the characteristic patterns of surface flows $H(x, t)$ can be decomposed into a series of linear combinations of temporal and spatial orthonormal function:

$$
H(x, t)=\sum_{m=1}^{M} Z_{m}(x) L_{m}(t)
$$

where

$Z_{m}$ (also known as EOFs) are the spatial eigenfunctions representing the dominant spatial patterns of surface flow range variability;

$L_{m}$ (also known as PCAs) are the temporal eigenfunctions indicating the long-term changes of surface vector fields;

$m=1$ to $M$, with $M$ being the number of temporal and spatial samples. 
Here, both the EOFs and PCAs should be orthonormal and normalized as follows:

$$
\begin{gathered}
\sum_{t=1}^{T} L_{i}(t) L_{j}(t)= \begin{cases}0 & i \neq j \\
1 & i=j\end{cases} \\
\sum_{x=1}^{X} Z_{i}(x) Z_{j}(x)=\left\{\begin{array}{cc}
0 & i \neq j \\
\gamma_{i} & i=j
\end{array}\right.
\end{gathered}
$$

where

$X$ and $T$ are the maximum values of $x$ and $t$, respectively;

$\gamma_{i}$ is the eigenvalue, which represents the contribution made by the $i$ th EOF mode to the total variance, where the first few largest eigenvalues typically contain the most signals and represent the dominant temporal-spatial patterns of the observed tidal series. The relative contribution of the $m$ th eigenfunction pm can be computed by the following expression:

$$
p_{m}=\left(\lambda_{m} / \sum_{m=1}^{M} \lambda_{m}\right) \times 100
$$

Subsequently, it is possible to reconstruct a matrix $H^{\prime}(x, t)$ using a subset of the dominant eigenvectors, which explained the maximum variance with the first $k$ EOFs modes:

$$
H^{\prime}(x, t)=\sum_{m=1}^{k} Z_{m}(x) L_{m}(t)
$$

\section{References}

1. Szuts, Z.B.; Bower, A.S.; Donohue, K.A.; Girton, J.B.; Hummon, J.M.; Katsumata, K.; Lumpkin, R.; Ortner, P.B.; Phillips, H.E.; Rossby, H.T.; et al. The Scientific and Societal Uses of Global Measurements of Subsurface Velocity. Front. Mar. Sci. 2019, 6, 6. [CrossRef]

2. Farcy, P.; Durand, D.; Charria, G.; Painting, S.J.; Tamminem, T.; Collingridge, K.; Grémare, A.J.; Delauney, L.; Puillat, I. Toward a European Coastal Observing Network to Provide Better Answers to Science and to Societal Challenges; The JERICO Research Infrastructure. Front. Mar. Sci. 2019, 6. [CrossRef]

3. Vandenbulcke, L.; Beckers, J.-M.; Barth, A. Correction of inertial oscillations by assimilation of HF radar data in a model of the Ligurian Sea. Ocean Dyn. 2016, 67, 117-135. [CrossRef]

4. Lai, Y.; Zhou, H.; Yang, J.; Zeng, Y.; Wen, B. Submesoscale Eddies in the Taiwan Strait Observed by High-Frequency Radars: Detection Algorithms and Eddy Properties. J. Atmos. Ocean. Technol. 2017, 34, 939-953. [CrossRef]

5. Hisaki, Y.; Kashima, M.; Kojima, S. Surface current patterns observed by HF radar: Methodology and analysis of currents to the north of the Yaeyama Islands, East China Sea. Ocean Dyn. 2016, 66, 329-352. [CrossRef]

6. John, M.; Jena, B.K.; Sivakholundu, K.M. Surface current and wave measurement during cyclone phaillin by high frequency radars along the indian coast. Curr. Sci. 2015, 108, 405-409.

7. Wang, Y.; Ma, X.; Joyce, M.J. Reducing sensor complexity for monitoring wind turbine performance using principal component analysis. Renew. Energy 2016, 97, 444-456. [CrossRef]

8. Mardia, K.V. Some properties of classical multidimensional scaling. Commun. Stat. Theory Methods 1978, 7, 1233-1241. [CrossRef]

9. Liu, Y.; Weisberg, R.H.; Vignudelli, S.; Mitchum, G.T. Patterns of the loop current system and regions of sea surface height variability in the eastern Gulf of Mexico revealed by the self-organizing maps. J. Geophys. Res. Oceans 2016, 121, 2347-2366. [CrossRef]

10. Liu, Y.; Weisberg, R.H.; Shay, L.K. Current Patterns on the West Florida Shelf from Joint Self-Organizing Map Analyses of HF Radar and ADCP Data. J. Atmos. Ocean. Technol. 2007, 24, 702-712. [CrossRef] 
11. Soto-Navarro, J.; Lorente, P.; Fanjul, E.A.; Sanchez-Garrido, J.C.; Garcia-Lafuente, J. Surface circulation at the $\mathrm{S}$ trait of $\mathrm{G}$ ibraltar: A combined HF radar and high resolution model study. J. Geophys. Res. Oceans 2016, 121, 2016-2034. [CrossRef]

12. Reusch, D.B.; Hewitson, B.C.; Alley, R.B. Towards ice-core-based synoptic reconstructions of west antarctic climate with artificial neural networks. Int. J. Clim. 2005, 25, 581-610. [CrossRef]

13. Lobo, V.J.A.S. Application of Self Organizing Maps to the Maritime Environment. In Proceedings of the 4th International Workshop on Information Fusion and Geographical Information Systems, St Petersburg, Russia, 17-20 May 2009; Popovich, V.V., Schrenk, M., Claramunt, C., Korolenko, K.V., Eds.; Springer-Verlag Berlin: St Petersburg, Russia, 2009; pp. 19-36.

14. Lin, G.-F.; Chen, L.-H. Identification of homogeneous regions for regional frequency analysis using the self-organizing map. J. Hydrol. 2006, 324, 1-9. [CrossRef]

15. Solidoro, C.; Bandelj, V.; Barbieri, P.; Cossarini, G.; Umani, S.F. Understanding dynamic of biogeochemical properties in the northern Adriatic Sea by using self-organizing maps and k-means clustering. J. Geophys. Res. Space Phys. 2007, 112, 1-13. [CrossRef]

16. Tsai, W.-P.; Huang, S.-P.; Cheng, S.-T.; Shao, K.-T.; Chang, F.-J. A data-mining framework for exploring the multi-relation between fish species and water quality through self-organizing map. Sci. Total. Environ. 2017, 579, 474-483. [CrossRef]

17. Nkiaka, E.; Nawaz, N.R.; Lovett, J.C. Using self-organizing maps to infill missing data in hydro-meteorological time series from the Logone catchment, Lake Chad basin. Environ. Monit. Assess. 2016, 188, 1-12. [CrossRef]

18. Tsui, I.-F.; Wu, C.-R. Variability analysis of Kuroshio intrusion through Luzon Strait using growing hierarchical self-organizing map. Ocean Dyn. 2012, 62, 1187-1194. [CrossRef]

19. Camus, P.; Cofino, A.S.; Mendez, F.J.; Medina, R. Multivariate Wave Climate Using Self-Organizing Maps. J. Atmos. Ocean. Technol. 2011, 28, 1554-1568. [CrossRef]

20. Kalteh, A.M.; Hjorth, P.; Berndtsson, R. Review of the self-organizing map (SOM) approach in water resources: Analysis, modelling and application. Environ. Model. Softw. 2008, 23, 835-845. [CrossRef]

21. Liu, Y.; Weisberg, R.H.; He, R. Sea Surface Temperature Patterns on the West Florida Shelf Using Growing Hierarchical Self-Organizing Maps. J. Atmos. Ocean. Technol. 2006, 23, 325-338. [CrossRef]

22. Reusch, D.B.; Alley, R.B.; Hewitson, B.C. North Atlantic climate variability from a self-organizing map perspective. J. Geophys. Res. Space Phys. 2007, 112, 1-20. [CrossRef]

23. Liu, Y.; Weisberg, R.H. Patterns of ocean current variability on the West Florida Shelf using the self-organizing map. J. Geophys. Res. Space Phys. 2005, 110, 1-12. [CrossRef]

24. Liu, Y.; Weisberg, R.H.; Mooers, C.N.K. Performance evaluation of the self-organizing map for feature extraction. J. Geophys. Res. Space Phys. 2006, 111, 111. [CrossRef]

25. Mihanović, H.; Cosoli, S.; Vilibić, I.; Ivanković, D.; Dadić, V.; Gačić, M. Surface current patterns in the northern Adriatic extracted from high-frequency radar data using self-organizing map analysis. J. Geophys. Res. Space Phys. 2011, 116, 116. [CrossRef]

26. Vilibić, I.; Šepić, J.; Mihanović, H.; Kalinic, H.; Cosoli, S.; Janeković, I.; Žagar, N.; Jesenko, B.; Tudor, M.; Dadić, V.; et al. Self-Organizing Maps-based ocean currents forecasting system. Sci. Rep. 2016, 6, 22924. [CrossRef]

27. Jin, B.; Wang, G.; Liu, Y.; Zhang, R. Interaction between the East China Sea Kuroshio and the Ryukyu Current as revealed by the self-organizing map. J. Geophys. Res. Space Phys. 2010, 115, 1-7. [CrossRef]

28. Barros, A.P.; Bowden, G.J. Toward long-lead operational forecasts of drought: An experimental study in the Murray-Darling River Basin. J. Hydrol. 2008, 357, 349-367. [CrossRef]

29. Obach, M.; Wagner, R.; Werner, H.; Schmidt, H.-H. Modelling population dynamics of aquatic insects with artificial neural networks. Ecol. Model. 2001, 146, 207-217. [CrossRef]

30. Malek, S.; Gunalan, R.; Kedija, S.Y.; Lau, C.F.; Mosleh, M.A.A.; Milow, P.; Lee, S.A.; Saw, A. Random forest and Self Organizing Maps application for analysis of pediatric fracture healing time of the lower limb. Neurocomputing 2018, 272, 55-62. [CrossRef]

31. Booth, D. The Water Structure and Circulation of Killary Harbour and of Galway Bay. Ph.D. Thesis, National University of Ireland, Galway, Ireland, 1975.

32. Fernandes, L. A Study of the Oceanography of Galway Bay, Mid-Western Coastal Waters (Galway Bay to Bralle Bay), Shannon Estuary and the Rive Shannon Plume. Ph.D. Thesis, National University of Ireland, Galway, Ireland, 1988. 
33. Wen, L. Three-Dimensional Hydrodynamic Modelling in Galway Bay. Ph.D. Thesis, University College Galway, Galway, Ireland, 1995.

34. Joshi, S.; Duffy, G.P.; Brown, C. Mobility of maerl-siliciclastic mixtures: Impact of waves, currents and storm events. Estuar. Coast. Shelf Sci. 2017, 189, 173-188. [CrossRef]

35. Paduan, J.D.; Washburn, L. High-Frequency Radar Observations of Ocean Surface Currents. Annu. Rev. Mar. Sci. 2013, 5, 115-136. [CrossRef] [PubMed]

36. Lipa, B.J.; Barrick, D.E.; Isaacson, J.; Lilieboe, P.M. Codar wave measurements from a north sea semisubmer sible. IEEE J. Ocean. Eng. 1990, 15, 119-125. [CrossRef]

37. Emery, B.M.; Washburn, L.; Harlan, J.A. Evaluating Radial Current Measurements from CODAR High-Frequency Radars with Moored Current Meters. J. Atmos. Ocean. Technol. 2004, 21, 1259-1271. [CrossRef]

38. Liu, Y.; Weisberg, R.H.; Merz, C.R.; Lichtenwalner, S.; Kirkpatrick, G.J. HF Radar Performance in a Low-Energy Environment: CODAR SeaSonde Experience on the West Florida Shelf. J. Atmos. Ocean. Technol. 2010, 27, 1689-1710. [CrossRef]

39. Roarty, H.; Cook, T.; Hazard, L.; George, D.; Harlan, J.; Cosoli, S.; Wyatt, L.; Fanjul, E.A.; Terrill, E.; Otero, M.; et al. The Global High Frequency Radar Network. Front. Mar. Sci. 2019, 6, 1-26. [CrossRef]

40. Mantovani, C.; Corgnati, L.; Horstmann, J.; Rubio, A.; Reyes, E.; Quentin, C.; Cosoli, S.; Asensio, J.L.; Mader, J.; Griffa, A. Best Practices on High Frequency Radar Deployment and Operation for Ocean Current Measurement. Front. Mar. Sci. 2020, 7. [CrossRef]

41. Tinis, S.W.; Hodgins, D.O.; Fingas, M. Assimilation of radar measured surface current fields into a numerical model for oil spill modelling. Spill Sci. Technol. Bull. 1996, 3, 247-251. [CrossRef]

42. Bellomo, L.; Griffa, A.; Cosoli, S.; Falco, P.; Gerin, R.; Iermano, I.; Kalampokis, A.; Kokkini, Z.; Lana, A.; Magaldi, M.G.; et al. Toward an integrated HF radar network in the Mediterranean Sea to improve search and rescue and oil spill response: The TOSCA project experience. J. Oper. Oceanogr. 2015, 8, 1-13. [CrossRef]

43. Ren, L.; Nash, S.; Hartnett, M. Forecasting of Surface Currents via Correcting Wind Stress with Assimilation of High-Frequency Radar Data in a Three-Dimensional Model. Adv. Meteorol. 2016, 2016, 1-12. [CrossRef]

44. Marmain, J.; Molcard, A.; Forget, P.; Barth, A.; Ourmières, Y. Assimilation of HF radar surface currents to optimize forcing in the northwestern Mediterranean Sea. Nonlinear Process. Geophys. 2014, 21, 659-675. [CrossRef]

45. Xu, J.; Huang, J.; Gao, S.; Cao, Y. Assimilation of high frequency radar data into a shelf sea circulation model. J. Ocean. Univ. China 2014, 13, 572-578. [CrossRef]

46. Ren, L.; Nash, S.; Hartnett, M. Renewable energies offshore. In Chapter 24 Data Assimilation with High-Frequency (HF) Radar Surface Currents at a Marine Renewable Energy Test Site; Soares, C.G., Ed.; CRC Press: London, UK, 2015.

47. Solabarrieta, L.; Frolov, S.; Cook, M.; Paduan, J.; Rubio, A.; González, M.; Mader, J.; Charria, G. Skill Assessment of HF Radar-Derived Products for Lagrangian Simulations in the Bay of Biscay. J. Atmos. Ocean. Technol. 2016, 33, 2585-2597. [CrossRef]

48. Roarty, H.; Glenn, S.; Allen, A. Evaluation of Environmental Data for Search and Rescue. In Proceedings of the OCEANS 2016, Shanghai, China, 10-13 April 2016; IEEE: Piscataway, NJ, USA, 2016; pp. 1-3.

49. Cosoli, S.; Grcic, B.; De Vos, S.; Hetzel, Y. Improving Data Quality for the Australian High Frequency Ocean Radar Network through Real-Time and Delayed-Mode Quality-Control Procedures. Remote. Sens. 2018, 10, 1476. [CrossRef]

50. Kim, S.Y.; Terrill, E.; Cornuelle, B. Objectively mapping HF radar-derived surface current data using measured and idealized data covariance matrices. J. Geophys. Res. Space Phys. 2007, 112, 112. [CrossRef]

51. O’Donncha, F.; Hartnett, M.; Nash, S.; Ren, L.; Ragnoli, E. Characterizing observed circulation patterns within a bay using HF radar and numerical model simulations. J. Mar. Syst. 2015, 142, 96-110. [CrossRef]

52. Rubio, A.; Mader, J.; Corgnati, L.; Mantovani, C.; Griffa, A.; Novellino, A.; Quentin, C.; Wyatt, L.; Schulz-Stellenfleth, J.; Horstmann, J.; et al. HF Radar Activity in European Coastal Seas: Next Steps toward a Pan-European HF Radar Network. Front. Mar. Sci. 2017, 4. [CrossRef]

53. Ren, L.; Nagle, D.; Hartnett, M.; Nash, S. The Effect of Wind Forcing on Modeling Coastal Circulation at a Marine Renewable Test Site. Energies 2017, 10, 2114. [CrossRef]

54. Ren, L.; Nash, S.; Hartnett, M. Observation and modeling of tide-and wind-induced surface currents in Galway Bay. Water Sci. Eng. 2015, 8, 345-352. [CrossRef] 
55. Hamrick, J.M. Efdc Technical Memorandum; Tetra Tech: Fairfax, VA, USA, 2006.

56. Tetra Tech, Inc. The Environmental Fluid Dynamics Code Theory and Computation Volume 1: Hydrodynamics and Mass Transport; Tetra Tech, Inc.: Fairfax, VA, USA, 2007; p. 60.

57. Hamrick, J.M. A Three-Dimensional Environmental Fluid Dynamics Computer Code: Therotical and Computatonal Aspects; Virginia Institute of Marine Science, William \& Mary: Gloucester Point, VA, USA, 1992.

58. Zou, R.; Carter, S.; Shoemaker, L.; Parker, A.; Henry, T. Integrated Hydrodynamic and Water Quality Modeling System to Support Nutrient Total Maximum Daily Load Development for Wissahickon Creek, Pennsylvania. J. Environ. Eng. 2006, 132, 555-566. [CrossRef]

59. Jin, K.-R.; Ji, Z.-G. Case Study: Modeling of Sediment Transport and Wind-Wave Impact in Lake Okeechobee. J. Hydraul. Eng. 2004, 130, 1055-1067. [CrossRef]

60. O'Donncha, F.; Hartnett, M.; Nash, S. Physical and numerical investigation of the hydrodynamic implications of aquaculture farms. Aquac. Eng. 2013, 52, 14-26. [CrossRef]

61. Bôas, A.B.V.; Ardhuin, F.; Ayet, A.; Bourassa, M.A.; Brandt, P.; Chapron, B.; Cornuelle, B.D.; Farrar, J.T.; Fewings, M.R.; Fox-Kemper, B.; et al. Integrated Observations of Global Surface Winds, Currents, and Waves: Requirements and Challenges for the Next Decade. Front. Mar. Sci. 2019, 6. [CrossRef]

62. Egbert, G.D.; Erofeeva, S.Y. Effificient inverse modeling of barotropic ocean tides. J. Atmos. Ocean. Technol. 2002, 19, 183. [CrossRef]

63. Padman, L.; Erofeeva, S. A barotropic inverse tidal model for the Arctic Ocean. Geophys. Res. Lett. 2004, 31, 1-4. [CrossRef]

64. Kohonen, T. Self-organized formation of topologically correct feature maps. Boil. Cybern. 1982, 43, 59-69. [CrossRef]

65. Chalasani, R.; Principe, J.C. Self-organizing maps with information theoretic learning. Neurocomputing 2015, 147, 3-14. [CrossRef]

66. Vilibić, I.; Kalinic, H.; Mihanović, H.; Cosoli, S.; Tudor, M.; Žagar, N.; Jesenko, B. Sensitivity of HF radar-derived surface current self-organizing maps to various processing procedures and mesoscale wind forcing. Comput. Geosci. 2015, 20, 115-131. [CrossRef]

67. Vilibić, I.; Mihanović, H.; Kušpilić, G.; Ivčević, A.; Milun, V. Mapping of oceanographic properties along a middle Adriatic transect using Self-Organising Maps. Estuar. Coast. Shelf Sci. 2015, 163, 84-92. [CrossRef]

68. Li, Q.; Chen, P.; Sun, L.; Ma, X. A global weighted mean temperature model based on empirical orthogonal function analysis. Adv. Space Res. 2018, 61, 1398-1411. [CrossRef]

69. Hannachi, A.; Jolliffe, I.T.; Stephenson, D.B. Empirical orthogonal functions and related techniques in atmospheric science: A review. Int. J. Clim. 2007, 27, 1119-1152. [CrossRef]

70. Monahan, A.H.; Fyfe, J.C.; Ambaum, M.H.; Stephenson, D.B.; North, G.R. Empirical Orthogonal Functions: The Medium is the Message. J. Clim. 2009, 22, 6501-6514. [CrossRef]

71. Mau, J.-C.; Wang, D.-P.; Ullman, D.S.; Codiga, D.L. Characterizing Long Island Sound outflows from HF radar using self-organizing maps. Estuar. Coast. Shelf Sci. 2007, 74, 155-165. [CrossRef]

72. Taylor, R. Interpretation of the Correlation Coefficient: A Basic Review. J. Diagn. Med. Sonogr. 1990, 6, 35-39. [CrossRef]

73. Paduan, J.D.; Shulman, I. HF radar data assimilation in the Monterey Bay area. J. Geophys. Res. Space Phys. 2004, 109, 434-446. [CrossRef]

(C) 2020 by the authors. Licensee MDPI, Basel, Switzerland. This article is an open access article distributed under the terms and conditions of the Creative Commons Attribution (CC BY) license (http://creativecommons.org/licenses/by/4.0/). 